$$
\begin{gathered}
3 . \\
\text { Derecho judiciario }
\end{gathered}
$$





\title{
FunCiÓN DE LAS CORTES SUPREMAS DE BRASIL Y CHILE EN LA GENERACIÓN Y GESTIÓN DEL PRECEDENTE JUDICIAL ENTRE LO PÚBLICO Y LO PRIVADO*
}

[Role of the Supreme Courts of Brasil and Chile regarding the Generation and Management of Judicial Precedent between Public and Private Matters]

\author{
Álvaro Pérez RagOne** \\ Paula Pessoa Pereira***
}

\begin{abstract}
RESUMEN
Las externalidades del precedente judicial son positivas y valiosas, generan coherencia, seguridad, previsibilidad, y un cauce adecuado de diálogo entre los tribunales. Incluso se podría llegar a argumentar sobre su necesidad en tanto componente de la efectiva, adecuada e igualitaria tutela de los derechos. El precedente es mucho más que simplemente hablar de uno o más fallos, con
\end{abstract}

\begin{abstract}
Judicial precedent externalities are positive and valuable; they generate consistency, security, predictability and an adequate dialogue channel between Courts. It could even be argued that they are a key component for the effective, adequate and equal protection of rights. The precedent is much more than simply talking about one or more rulings; it offers much more than a "deterrent"
\end{abstract}

RECIBIDO el 30 de abril y ACEPTADO el 30 de mayo de 2015

* Este trabajo hace parte del proyecto Fondecyt regular No 1150468 "Gestión y dirección eficiente de procesos civiles".

** Doctor en derecho por la Universidad de Köl, Alemania. Dirección postal: Av. Coraceros 50, Edificio Alto Libertad, Dpto. 2401, Viña del Mar, Chile. Correo electrónico: aperezragone@googlemail.com

*** Magíster en derecho y doctoranda en la Universidad Federal de Parana, Curitiba, Brasil. Dirección postal: Faculdade de Direito, UFPR, Praça Santos Andrade, 50, $1^{\circ}$ andar, Centro CEP: 80.020-300m, Curitiba , PR , Brasil. Correo electrónico: pessoapp@hotmail.com 
algo mucho más que el efecto vinculante "disuasivo". El precedente requiere la consideración de los intereses públicos como privados. Lo principal es que es un producto y se genera en las relaciones dialógicas (discursivas de diálogo y argumentación) entre los tribunales de justicia. El precedente permite gestionar en prospectiva minimizando el error de decisión de los tribunales. Este artículo examina estos principios, los trata de sustentar y finalmente analiza cómo han sido receptados en los modelos de corte suprema brasileña y chilena.

\section{Palabras ClAVE}

Precedente judicial - Ius litigatoris - Ius constitutionis - Cortes supremas. binding effect. The precedent needs to consider public and private interests. The main point is that it is a product generated from the dialogical relationships (dialogue and argumentation discursives) between the courts of justice. The precedent allows us to manage in foresight, minimising the mistakes in the decisions made by the courts. This article reviews these principles, tries to support them and finally analyses how they have been received in the Brasilian and Chilean Supreme Court models.

\section{KEYWORDS}

Judicial precedent - Ius litigatoris - Ius constitutionis - Supreme Courts.

\section{INTRODUCCIÓN}

1. Tratar el rol que tienen (descriptivamente) o que debieran tener (de propuesta o incluso normativamente) las cortes supremas o tribunales superiores no es un tema novedoso, ya que ha venido siendo discutido profusamente durante años. Agregar algo nuevo resulta un desafío, es imposible por de pronto procesar toda la bibliografía relevante actual sobre el tema. Pero hay que asumir que siendo un desafío poco original y difícil, también es agradable especialmente en el caso paralelo de dos países con tradicional resquemor y hasta prejuicio hacia la jurisprudencia y mucho más al "precedente": sea por temor, por extraños prejuicios relacionados con las distintas familias jurídicas o directamente por desconocimiento del sistema. Las externalidades del precedente judicial son positivas y valiosas, permiten "gestionar" coherencia, seguridad, previsibilidad, y un cauce adecuado de diálogo entre los tribunales ${ }^{1}$. Incluso se podría llegar a argumentar sobre su necesidad en tanto componente de la efectiva, ade-

${ }^{1}$ El término "gestionar" se emplea en este texto en el sentido de manejo de expectativas e intereses actuales y futuros en un marco de previsibilidad, coherencia y seguridad; así en EsKridge, William - FrickeY, Philip (coordinadores), en Hart and Sack's The Legal Process: Basic Problems in the Making and Application of Law (Westbury, N.Y., 1994), "Introduction"; cfr. igualmente con BuENO DE MESQUITA, Ethan - Stephenson, Matthew Informative Precedent and Intrajudicial Communication, en American Political Science Review, 196 (2002), pp. 755-766. 
cuada e igualitaria tutela de los derechos. El precedente es mucho más que simplemente hablar de uno o más fallos a veces mas identificados con "la jurisprudencia" como fuente del derecho con efecto vinculante "disuasivo". Lo principal es que se trata de un producto y se genera en las relaciones dialógicas (discursivas de diálogo y argumentación) entre los tribunales de justicia: i) Sea en relación con un caso decidido que podría servir para resolver uno actual; ii) Sea porque un mismo caso actual genera entre distintos tribunales respuestas disímiles y ello necesita ser armonizado; iii) Sea porque el tema a ser decidio en un caso actual podría implicar desarrollar esa materia jurídica en un sentido que complemente la labor incompleta del legislador que no puede -ni podría- contemplar todas las hipótesis posibles ${ }^{2}$. En estos tres ejemplos mencionados lo relevante es el diálogo entre los tribunales y como la fuerza de la razón argumentativa de unos legitiman una decisión que termina siendo seguida por otros, o bien, elevan la vara de la disputa y debe llegarse a una última palabra ${ }^{3}$.

2. En muchos sistemas jurídicos, los tribunales supremos realizan una gran variedad de otras funciones, además de la adjudicativa. Sólo por mencionar algunos ejemplos, funciones de carácter disciplinarias, de administración de recursos humanos e infraestructural, finalmente un rol reglamentario ${ }^{4}$. Nos centraremos así exclusivamente en la función adjudicativa del tribunal supremo (el último en grado y pirámide organizacional), y por qué algunas de sus decisiones podrían asumir un rol más allá de meras directrices (queridas o no, conscientes o inconscientes) para futuros casos. Es decir, asumen un rol prospectivo a partir de los casos individuales que

${ }^{2}$ Kornhauser, Leweis, Appeal and Supreme Courts, en SAnChirico, C. W. (coordibnador), Procedural Law and Economics (Massachusets, 2012), pp. 19-41 (esp. 21 s.); Hansford, Thomas - Sprigs II, James, The Politics of Precedent Oxford, 2006), pp. 18-31; Morvan, Patrick, En droit, la jurisprudence est une source de droit, en Revue de la Recherche Juridique (2001) 1, p. 77; cfr. PUIGELIER, Catherine, La création du droit (Libres propos sur la norme jurisprudentielle), en Revue de la Recherche Juridique (2004) 1, p. 17.

${ }^{3}$ En este texto se habla o se refiere a "última palabra" no en el sentido de imposición por autoridad jerárquica, sino la razonable argumentación de quien es asumido en un ordenamiento jurídico como la última instancia o estadio de decisión. Así en el sentido de "Brown v. Allen," v. 344 U.S. p. 443: 2 We are not final because we are infallible, but we are infallible only because we are final.

${ }^{4}$ TARUfFo, Michele Le funzioni delle corte supremi. Cenni generali, en Mitidiero, Daniel - Rizzo, Guilherme (coordinadores) - Echer Ferreira FejJó, Maria Angélica (organizadora), Processo Civil. Etudios em homenagem ao professor Doutor Carlos Alberto Alvaro de Oliveira (São Paulo, 2012), p. 341. 
deciden y de esta forma sientan las bases de futuro para casos similares 5 . No pretendemos adentrar en detalles relativos a los tribunales constitucionales o supuestos complejos de tribunales supranacionales, como la Corte Interamericana de Derechos Humanos u otros similares, que necesitaría de una investigación propia en el diálogo entre tribunales de derechos humanos o constitucionales "convertidos" 6 en su rol que finalmente terminan asumiendo rol de tribunal ordinario en su competencia ${ }^{7}$.

A los jueces compete la función de conciliar los valores y objetivos del Estado de derecho, éste como un ideal de la moralidad jurídica y política. Ello con su dimensión procesal, que se desarrolla a través del derecho de acceso a los tribunales y del derecho al debido y justo proceso, así como con el carácter argumentativo e interpretativo, los cuales son inherente a la naturaleza del derecho ${ }^{8}$. Al proceso de aplicación del derecho por los jueces,

${ }^{5}$ Así Cardozo, Benjamin, The Nature of the Judicial Process (New Haven - London, 1921), pp. 33-34 "It will not do to decide the same question one way between one set of litigants and the opposite way between another. "If a group of cases involves the same point, the parties expect the same decision. It would be a gross injustice to decide alternate cases on opposite principles. If a case was decided against me yesterday when I was a defendant, I shall look for the same judgment today if I am plaintiff. To decide differently would raise a feeling of resentment and wrong in my breast; it would be an infringement, material and moral, of my rights"; como ejemplo para el modelo del "civil law" mediante la llamada "Jurisprudence constante" puede verse Malaurie, Philippe, Les précédents et le droit, en Revue Internationale de Droit Comparé, 58 (2016) 2, pp. 319-326; en general para el tema puede verse: Posner, Richard A. , The Role of the Judge in the Twenty-First Century, en Boston University Law Review, 86 (2006), pp. 1049, 1050; Oldfather, Chad M., Judging, Expertise, and the Rule of Law, en Washington University Law Review, 89 (2012), p. 847; GaIER, Reinhard, Der moderne liberale Zivilprozess, en Neue Juristische Wochenschrift (2013), pp. 2871, 2875-2876. Para Alemania, MaultzsCH, Felix, Streitentscheidung und Normbildung durch den Zivilprozess (Tübingen, 2010), p. 34 s.; STÜRner, Rolf, O Papel dos Tribunais Superiores na Alemanha, en II Seminário Internacional Brasil-Alemanha, en Cadernos do CEJ., 27 (2011), pp. 99-100; para la Corte Suprema Administrativa en Escandinavia del Este véase: LindBlom, Henrik, The Role of the Supreme Courts in Scandinavia, en Scandinavian Stud.ies in Law, 39 (2000), pp. 325, 329, 335.

${ }^{6}$ El Tribunal Constitucional Federal Alemán ("Bundesverfassungsgericht", BVerfG) trata de mantener su rol para no ser considerado un tribunal de "supraapelación o superrevisión”: Reporte official del BVerfG (BVerfGE) 2, 336, 339; 21, 209, 216; 53, 30, 53

${ }^{7}$ Cf. TARuffo, cit. (n. 4), pp. 341, 343, 348.

${ }^{8}$ Puede verse lo sostenido por Mitidiero, Daniel, Cortes superiores e cortes supremas: do controle à interpretação, da jurisprudência ao precedente (São Paulo, 2013) p. 13-32, que defiende, en la literatura jurídica procesal brasileña, que el proceso civil en el Estado Constitucional debe ser comprendido como un medio para la tutela 
por consiguiente, se entrega la doble tarea de resolver el caso particular y de atribuir significado a las normas jurídicas, definiendo los derechos y deberes de los ciudadanos, con el fin de completar las lagunas existentes en el ordenamiento jurídico, enriqueciendo su "stock" normativo".

3. Las decisiones judiciales, desde esta perspectiva, asumen la verdadera función de operar como elementos de prescripción normativa en el ordenamiento jurídico, en respuesta a las demandas dinámicas que el ordenamiento exige, puesto que el legislador no puede satisfacer la demanda por regulación de los hechos sociales de forma adecuada y satisfactoria, en la velocidad en que la sociedad se desarrolla. La función normativa que incide sobre las decisiones judiciales requiere la formulación de un adecuado posicionamiento frente a la motivación y fundamentación de las sentencias como la interpretación que en ellas hagan los jueces. Es por eso que el proceso de toma de decisiones judiciales debe guiarse por los mismos valores que densifican el principio del Estado de derecho, en particular aquellos relacionados a la producción de normas jurídicas. Así es posible "tratar las decisiones judiciales previas como enunciados autoritativos del derecho que funcionan como buenas razones para decisiones subsecuentes" y exigir a los “jueces de tribunales específicos que consideren ciertas decisiones previas, sobre todo las de las altas cortes, como una razón vinculante" ${ }^{10}$. En esta línea, defendemos que el universalismo representa una teoría adecuada para la justificación de la decisión judicial en conformidad con los principios de la igualdad, imparcialidad y racionalidad. Esta justificación se limita a la etapa del razonamiento judicial que pondera y discurre sobre el alcance e interpretación de las normas jurídicas, puesto que en el juicio donde se delibere sobre los hechos prevalece la justificación particularista ${ }^{11}$.

efectiva tempestiva y adecuada de los derechos, finalidad que exige que el proceso sirva a un doble discurso, tanto en la dimensión particular, mediante el otorgamiento de una decisión justa, cuanto en la dimensión general, mediante la formación de precedentes orientados a la unidad del derecho. En realidad lo sostenido por el autor no es sino una aplicación de la respuesta a cuáles son las finalidades que persigue el proceso, que será referida más adelante.

${ }^{9} \mathrm{La}$ expresión enriquecimiento de "stock" legal es tomada de la clasificación hecha por Eisenberg, Melvin. The Nature of the Common Law (Cambridge, 1998) pp. $4 \mathrm{~s}$., al respecto de las funciones sociales que las cortes desempeñam, a saber: "resolution disputes" e "enrichment of the supply of legal rules".

${ }^{10}$ Bell, John, Sources of Law, en BIRKS, P. (coordinador) English Private Law (Oxford, 2000), I, pp. 1, 29.

${ }^{11}$ Para esta discusión véase, por ejemplo, BVerfGE 49, 148, 159; HorST-EbERHARD, Henke, Die TatfrageBerlin - München, 1966), p. 191; MaY, Artur, Die Revision, (Köln, 1995), n. 38 s. 
Desde este punto de vista, el "creador" más importante del sistema es -además del legislador-el juez, especialmente las pautas fijadas por las cortes supremas $^{12}$. Este hecho revela la complementariedad y responsabilidad que debe existir entre los poderes legislativo y judicial en la actividad de producción de normas jurídicas ${ }^{13}$.

4. Con este punto de partida asumimos las siguientes interrogantes: ¿Cómo coordinar las razones universalizables, para así poder asirse de una respuesta uniforme a seguir en la interpretación de la norma jurídica? La respuesta a este problema puede ser posible gracias a la regla de distribución del poder judicial, es decir, a través de la organización jerárquica de los órganos jurisdiccionales y la necesidad de minimización del riesgo de error en la decisión de casos similares ${ }^{14}$. En tanto gestión por el precedente y más siendo del vértice se consideran los casos futuros similares y el trato igualitario del judicial mediante sus decisiones de la tutela de los derechos que lo requieran ${ }^{15}$.

5. Este trabajo se estructura con las siguientes partes: en (II) comienza analizando el rol de las cortes supremas en tanto interrogante de función orientada en lo público o lo privado; se continúa con el examen de lo que identificamos como nuevos paradigmas (III); en (IV) se propone relacionar

${ }^{12}$ MacCormick, Neil. Rhetoric and the Rule of Law. A Theory of Reasoning (New York, 2005) p. 144; AARNIO, Aulis. Lo racional como razonable. Un tratado sobre la justificación jurídica (traducción de Ernersto Garzón Valdez, Madrid, 1991), p. 183. La manifestación del criterio de universalidad traduce el requisito práctico de la realización de la justicia procedimental, así como la impresión del elemento de la racionalidad en la argumentación jurídica, evitando la toma de decisiones judiciales arbitrarias y parciales. La universalidad, al imponer a cada juez o tribunal el deber de coherencia en sus diferentes decisiones, supone que hay una respuesta correcta para cada órgano judicial individualmente, a pesar de que no podemos afirmar que apodícticamente haya una respuesta correcta en el derecho o que esta pueda ser encontrada. Así "la dinámica del ordenamiento jurídico es producida, en ultima instancia, por los juristas prácticos.

${ }^{13}$ En ese sentido, MaRINONI, Luiz Guilherme. STJ enquanto corte de precedentes (2a edición, São Paulo, 2014), pp. 136-146.

${ }^{14}$ AARNio, cit. (n. 12), pp. 209-236.

${ }^{15}$ Mitidiero, cit. (n. 8), p. 21. Como no hay una respuesta correcta y un sistema jurídico no puede convivir con las diferentes soluciones sobre la interpretación del mismo texto legal, aquella debe ser institucionalmente garantizada por el tribunal de más alta jerarquía en el poder judicial. Y así debe ser, porque al tribunal del vértice se le da el poder y el deber de de gestionar la unificación de la jurisprudencia y devolver al Estado de derecho la definición de la norma jurídica en disputa, contribuyendo al desarrollo del derecho. 
el universalismo como teoría justificativa del precedente judicial y con ello del imperativo de igualdad en la tutela judicial de los derechos; posteriormente en $(V)$ se describen cómo se insertan en lo antes desarrollado las cortes supremas o tribunales supremos en Brasil y Chile para concluir con algunas consideraciones (VI).

\section{LAS FUNCIONES DE LAS CORTES SUPREMAS: \\ ENTRE LO PRIVADO Y LO PÚBLICO. \\ ¿UN FALSO MANIQUEÍ́SMO?}

a) La interrogante inicial sigue siendo la clásica sobre el destinatario del rol decisorio de las cortes supremas: ¿Son o debieran estar disponibles en interés de los litigantes o del interés público o general? Una pregunta que no es novedosa si se la considera como una manifestación de la interrogante del propósito o finalidad del proceso civi ${ }^{16}$. Cualquiera sea la respuesta si el planteo es en términos de dos alternativas nos encontramos frente a un dilema que aparenta partir de opciones totalmente antagónicas ${ }^{17}$. Incluso se sostiene que la utilidad pública de las decisiones de las cortes supremas es servir y emplear el interés privado para la consecución del primero. ${ }^{18}$ Así

${ }^{16}$ Para este tema ver en general: Jolowicz, John, Civil Litigation: What is it for?, en Dwyer (coordinador), The Civil Procedure Rules Ten Years on, Oxford: 2009, pp. 51-63; Gaul, Friedhelm Zur Frage nach dem Zweck des Zivilprozesses, en Archiv für die civilistische Praxis, 168 (1968), pp. 27 s.; un clásico en el tema es: LuHMANN, Niklas, Legitimation durch Verfahren (Neuwied, 1969), passim; PAWLOWSKI, Hans-Martin, Aufgabe des Zivilprozesses, en Zeitschrift für Zivilprozess, 80 (1967), pp. 345 ss.; LeIPOLD, Dieter, Zivilprozeß und Ideologie, en Juristenzeitung (1982), p. 441; PFEIFFer, Thomas Internationale Zuständigkeit und prozessuale Gerechtigkeit (Frankfurt a.M., 1995), p. 234 ss.; STÜRNER, Rolf, Die Aufklärungspflicht der Parteien des Zivilprozesses (Tübingen, 1976), p. 48 ss.; STÜRner, Rolf, Prozeßzweck und Verfassung, en PRÜTTING, Hans (editor), Festschrift für Gottfried Baumgärtel (Köln, 1990), pp. 545 ss.; más contemporáneo puede verse UZELAC, Alan, Goals of Civil Justice and Civil Procedure in the Contemporary World, en AA. VV., Goals of Civil Justice and Civil Procedure in Contemporary Judicial Systems (New York - Dordrecht-Heidelberg, 2014), pp. 3-34. Véase igualmente: Van RheE, C.H. - UzelaC, Alan, The Pursuit of Truth in Contemporary Civil Procedure, en Van Rhee, C.H. - Uzelac, Alan (coordinadores), Truth and Efficiency in Civil Litigation (Cambridge-Antwerp, 2012) pp. 3-10; SorabjI, John, Englisch Civil Justice (Cambridge, 2014), pp. 9-12.

${ }^{17}$ Вовек, Michal, Quantity or Quality? Re-Assessing the Role of the Supreme Jurisdictions in Central Europe, en American Journal of Comparative Law, 57 (2009), p. 33; GaLIC, Anton, Reshaping the Role of the Supreme Courtsin the Countries of the former Yugoslavia, en Van Rhee, C.H. - UzelaC, Alan, Nobody's Perfect (CambridgeAntwerp, 2014) pp. 291-315.

${ }^{18}$ Cf., entre otros: ARNOLD, Hans, Die Neuordnung des Zugangs zum Bundesgeri- 
pues si aceptamos -aun con matices- que tiene relevancia el interés privado, pues cabría preguntarse si tiene cabida el público. No consideramos que la respuesta deba ser maniqueista (ius litigatoris vs. ius constitutionis) ${ }^{19}$.

Creemos que en realidad ambos propósitos tienen -o debieran tener cabida- y es posible partir de la afirmación (por ahora hipótesis) que sostiene que el rol de la Corte Suprema es un continuo predominantemente privado y con cabida necesaria de lo público. ${ }^{20}$ Por interés público se hace referencia a cualquier interés diferente al solo enarbolado por las partes. Se habla de un interés (de repercusión) general o de orientación para uniformar, desarrollar y perfeccionar el derecho, brindar una última interpretación como directriz frente a multiplicidad de salidas posibles frente a casos similares ${ }^{21}$. En este sentido es que se suele hablar de tribunal supremo para la primacía de interés privado y de corte suprema para dar cabida a ambos propósitos. ${ }^{22}$ Así el resultado final que brindaría desde esta distinción una corte es la previsibilidad y confianza en un sistema ${ }^{23}$. Claro que pretender esquematizar todo a designaciones y funciones que solo distingan entre una corte de casación y una suprema, es relativizar matices de terceras vías diferenciales como la revisión alemana por ejemplo ${ }^{24}$. Por cierto, no compete a nosotros, en este espacio, dibujar un cuadro analítico de los principales modelos de cortes supremas ("cassation", “appeal” y revisión) $)^{25}$,

chtshof in Zivilsachen, en Juristische Rundschau (1975), p. 485; RECHBERGER, Walter H. - SimotтA, Daphne-Ariane Zivilprozessrecht (8a edición, Wien, 2010), n. 1037.

${ }^{19}$ En este sentido puede mencionarse a DeTHLOFF, Nina, Zugang zur Revisionsinstanz, en Zeitschrift für Rechtspolitik (2000), pp. 428, 430.

${ }^{20}$ Rosenberg, Leo - Schwab Karl, Heinz - GotTwald, Peter, Zivilprozessrecht (17 edición, München, 2010), $\$ 134$ n. 22. El problema en este aparente dilema es determinar qué es lo público y lo privado. Lo último podría referir a los intereses de las partes, su gravamen e intención de correcta justicia individual. Las cortes supremas corregirían como último "veedor" el error de los tribunales inferiores.

${ }^{21}$ DomeJ, Tom, What is an Important Case? Admisibility of Appeals to the Supreme Courts in the German-Speaking Jurisdictions, en VAN RHEE, C.H. - UZELAC, Alan (Cambridge - Antwerp, 2014), pp. 277-286.

${ }^{22}$ LAMES, Peter, Rechtsfortbildung als Prozeßzweck (Tübingen,1993), pp. 133134; RimmelspaCher, Bruno Zugangsvoraussetzungen zum Rechtsmittelgericht, en GotTwald, Peter - Roth, Herbert (editores), Festschrift für Ekkehard Schumann (Tübingen, 2001), pp. 327, 331, 342-348.

${ }^{23}$ Véase: Mitidiero, Daniel Fundamentação e precedente: Dois discursos a partir da decisão judicial, en Mitidiero, Daniel - Rizzo, Guilherme (coordinadores) - EcHER Ferreira Feijo, Maria Angélica (organizadora), Proceso civil. Etudios em homenagem ao professor doutor Carlos Alberto Alvaro de Oliveira (São Paulo, 2012,) pp. 85, 91.

${ }^{24}$ Unberath, Hannes Der Zweck der Rechtsmittel nach der ZPO-Reform. Theorie und Praxis, en Zeitschrift für Zivilprozess 120 (2007), pp. 323, 332-333.

${ }^{25}$ Para un cuadro comparativo sobre los tres principales modelos de cortes su- 
por escapar de nuestros objetivos y por ser una premisa prescindible para comprender las principales funciones adjudicativas y relacionadas con el precedente que estos tribunales ejercen. En realidad la función que cada tribunal desempeña concretamente en el sistema jurídico en que está inserido depende de los contornos de su estructura y modelo ${ }^{26}$.

b) Con este primer acercamiento puede decirse entonces que la distinción entre propósitos se atenúa ya que lo que es "público" también deriva o mejora lo "privado" 27 . Así se permite lograr la igualdad en la aplicación del derecho como corolario del principio fundamental de justicia que atañe también a cada uno en sus intereses particulares ${ }^{28}$. La Corte Suprema en tanto órgano adjudicador asumiría en su rol el interés público en tanto parte del "Poder Judicial" y por ello también defensora de los derechos individuales de los ciudadanos. Encuadre perfecto en el concepto tradicional de separación de poderes. ${ }^{29}$ Una distinción y separación absoluta nunca

premas: casación, de origen francesa y ampliamente recepcionado por el derecho italiano; appeal, originada de los paeses de common law, en Inglaterra y actualmente ejercida en los países escandinavos, y de revisión, de origen alemana, véase, por todos: Jolowicz, John Anthony, The Role of the Supreme Court at the National and International Level. A General Report, en Yessiou-FaLTSI (editor). Role of the Supreme Court at the National and International (Thessaloniki, 1998), pp. 50-56.

${ }^{26}$ Cfr. CADiet, Loïc. Le jugde de cassation en Europe, en Revista de Processo. São Paulo, 209 (2012), pp. 403-430; SiLvestri, Elisabetta. Corti supreme europee: acceso, filtri e selezione, en Le Corti Supreme: Atti del convegno svoltosi a Perugia il 5-6 maggio 2000 (Milano, 2001), pp. 105-116. Para un estudio analítico sobre las funciones de las cortes que ocupan el vértice de la organización judiciaria, ver la propuesta de Mitidiero, cit. (n. 8).

${ }^{27}$ Véase la decisión del Oberlandesgericht (OLG) Koblenz, en Neue Jurtistische Wochenschrift (2003)2100)2102) (enfatizando que hubo una conexión inherente entre propósitos de "interés publico" del recurso a la Supreme Court y el interés privado en tener acceso al tribunal).

${ }^{28}$ Mulcahy, Linda. The Collective Interest In Private Dispute Resolution, en Oxford Journal of Legal Studies 33 (2013) 1, pp. 59-80. Ello hasta el desarrollo y perfeccionamiento del derecho que brinda una solución correcta o al menos la buscada por las partes. Claro que a las partes no les interesa generar un precedente, o quizás les resulte totalmente irrelevante, pero para quienes serán partes en el futuro y con un litigio similar claro que en ese momento tendrán un interés en lo que en su momento se decidió para un caso, que tiene relevancia "general", pero especialmente "particular o privada" este proceso actual relacionado con uno pasado.

${ }^{29}$ Ver como ejemplo, Charles Louis de Secondat Montesquieu, De lesprit des loix (Geneva, 1748), p. 256: "Mais les juges de la nation ne sont [...] que la bouche qui prononce les paroles de la Loi: des Etres inanimés qui n'en peuvent modérer ni la force ni la rigueur"); BlaCKSTONE, William Commentaries on the Laws of England (Oxford, 1765), "Introduction", p. 69 (donde denomina "oráculos vivientes" a los jueces). Ahora bien si con lo de "interés público" de la Corte Suprema especialmente en el 
tuvo un éxito convincente, ni en los países del "common law", donde basta recordar las furibundas críticas de Bentham, ni en los países del "civil law” con la utopía de la perfección de las codificaciones ${ }^{30}$. El camino del tribunal que se topa con el silencio de la ley y la remisión a comisiones datan ya del Código prusiano de $1794^{31}$ simil del modelo inicial francés con el "référé législatif" 32 . Ni las cortes ni el juez son un mero aplicador ${ }^{33}$ primero, segundo el ejecutivo y legislativo también aplican y crean derecho en el Estado de derecho contemporáneo, la división de poderes antes que la separación rotunda que parecen ser la regla. Entre los poderes es normal la coordinación y colaboración funcional y no como islas funcionales ${ }^{34}$.

\section{La vieja disputa del "ius litigatoris" vs. "ius constitutionis".}

a) Las cortes supremas asumen en el Estado de derecho un rol preponderante en la adjudicación que tiene como valores la tutela de la igualdad, imparcialidad y previsibilidad, y como meta la coordinación uniforme de las razones universalizables de los jueces de instancia inferior, analizaremos los tipos de funciones que se pueden atribuir a la corte suprema ${ }^{35}$. Según

desarrollo del derecho, puede plantearse un conflicto con la idea de separación entre el poder judicial y el poder legislativo, claro que sería justificable si uno es solo aplicador deslindado del otro como creador.

${ }^{30}$ Hamilton, Alexander (ps. Publius), The Federalist, 78 de 14 de junio de 1788 (demanda que los jueces ejerzan o realicen juicios y no actos de voluntad).

${ }^{31} \$ 47$ de la "Introducción" al Código prusiano de 1794: "Si el juez encuentra dudoso el sentido de la ley, debe someter -sin citar previamente a las partes- su duda ante la Comisión Legal y solicitar su juicio”. Véase ese mismo Código, $1^{\mathrm{a}}$ parte, Título $13^{\circ}, \$ 32$.

${ }^{32}$ Hufteau, Yves-Louis Le "référé législatif" et les pouvoirs du juge dans le silence de la loi (Paris, 1965), passim. Véase igualmente el artículo 12 de la Ley del 16 de agosto 1790; el artículo 21 de la Ley del 27 de noviembre 1790; véase, por ejemplo : Alvazzi del Frate, Paolo, Aux origines du référé législatif: interprétation et jurisprudence dans les cahiers de doléances de 1789, en Revue Historique de Droit Français et Etranger, 86 (2008) 2, pp. 253 ss.

${ }^{33}$ Konzen, Horst Gesetzentwurf und Revisionsurteil, en WILKE, Dieter (editor), Festschrift zum 125 jährigen Bestehen der Juristischen Gesellschaft zu Berlin (Berlin New York, 1984), pp. 349, 363.

${ }^{34} \mathrm{MieRsCH}$, Matthias, Der sogenannte référé législatif. Eine Untersuchung zum Verhältnis Gesetzgeber, Gesetz und Richteramt seit dem 18. Jahrhundert (Baden-Baden, 2000), passim.

${ }^{35}$ TARUfFo, Michele, Le funzioni delle corti supreme: cenni generali., en Annuario di Diritto Comparato e di Studi Legislativi (Napoli, 2011), p. 14. Así se identifica, como hilo conductor de las funciones que las diferentes cortes supremas desarrollan en los sistemas jurídicos contemporáneos, la tutela y la promoción de la legalidad, a pesar de las numerosas diferencias que pueden hacerse presentes, de modo que esos son los dos objetivos principales que se tratan de definir. 
Taruffo el término "legalidad" asume para nuestro tema dos sentidos. Por un lado, en el contexto de la función desarrollada por los órganos jurisdiccionales, la legalidad puede ser entendida como la "correcta aplicación del derecho", centrando la atención en el propósito aplicativo de la interpretación del derecho, más que en la propia finalidad interpretativa. Por otro lado, la actividad objetivada con la correcta aplicación de la ley puede ser desempeñada de diferentes maneras, lo que lleva a las principales funciones derivadas del término como la de tutela, la de promoción y la del control de legitimidad de la decisión ${ }^{36}$.

Propone Taruffo que la tutela de la legalidad dice respecto con la llamada función reactiva de la corte, la cual se explica en los casos en que se observa una violación del derecho y la intervención de la corte es para dar una respuesta concreta a la violación, con su eliminación o neutralización de sus efectos. Mientras que la tutela de promoción de la legalidad, a su vez, se refiere a un papel proactivo de la corte, ya que ocurre cuando la decisión judicial tiene como objetivo lograr un efecto futuro, sea el de prevenir futuras violaciones de legalidad, sea de favorecer la evolución y la transformación del derecho ${ }^{37}$. Entre los significados atribuidos a la palabra "legalidad", uno particularmente importante es aquello que lleva al control de legitimidad de la decisión en un caso particular. Este control, que es equivalente a la función de tutela de la legalidad, significa que la función de la Corte es esencialmente la de determinar si la ley fue correctamente aplicada en el juicio de mérito. Este hecho configura un enfoque especial en la función reactiva de la corte, dado que el fundamento para el acceso a la corte consiste en la alegación de violación de la ley. En este sentido, por lo tanto, podemos hablar de una función privada ${ }^{38}$.

b) La tipología de una "función privada" fue elaborada por John Anthony Jolowicz, en el informe global presentado en el Coloquio de la Asociación Internacional de Derecho Procesal, que tenía por objeto discutir

${ }^{36}$ TARUFFO, cit. (n. 35), p. 15.

${ }^{37}$ Ibíd., p. 14.

${ }^{38}$ De acuerdo con Taruffo, la función reactiva de la corte es importante en la caracterización de la naturaleza de las cortes de casación del tipo franco-italiano y español, pero no es exclusiva de estas cortes. También las cortes que se definen como de "tercera instancia" (porque deciden definitivamente el mérito de la controversia), como la corte de Revision alemana, tienen una función reactiva de control de legitimidad. Ellas, en regla, no pueden valorar nuevamente la prueba, pero verifican si el juez inferior aplicó correctamente la ley (y, en caso negativo, pronuncian una decisión de mérito que sustituya la decisión viciada). Entre los modelos de casación y revisión existen diferencias sustanciales (sobretodo historicamente), pero en ambos modelos las cortes tienen por función verificar si la ley fue correctamente aplicada en la decisón del caso concreto sometido a su examen. TARUFFo, cit (n. 35), p. 17. 
el rol de las cortes supremas al nivel nacional e internacional. ${ }^{39} \mathrm{El}$ profesor de Cambridge, al analizar el papel de las cortes supremas en varios países de Europa continental, hizo una distinción entre los dos tipos principales de objetivos que son ejercidos por esas, es decir, la finalidad pública y la privada ${ }^{40}$. Para Jolowicz, numerosos objetivos sirven para sostener la finalidad pública de una Corte Suprema. No obstante, lo más relevante y que por sí mismo caracteriza la función pública está en la estabilidad, la uniformización y del desarrollo del derecho ${ }^{41}$. El autor británico enuncia que podría sostenerse una clasificación de las funciones que se pueden asignar a una Corte Suprema en pública y privada ${ }^{42}$. En ésta el tribunal ejerce el rol de último garante de la justicia y de corrección de la decisión en el caso, mientras que en la pública el papel es el de defensor por excelencia de un interés superior, a saber, garantizar la unidad del derecho positivo y realizar el principio de igualdad en la aplicación de la norma jurídica ${ }^{43}$.

2. La complementariedad de lo público y lo privado.

a) La función reactiva de la corte, como ha señalado Taruffo, es

\footnotetext{
${ }^{39}$ Sobre él véase: Andrews, Neil, John Anthony Jolowicz (1926-2012), en European Business Law Review, 4 (2012), pp. 455-460.

${ }^{40}$ Esa clasificación de las finalidades prevalecientes en la función de las cortes supremas ya había sido objeto de discusión por Taruffo el mismo autor, cuando hizo un estudio comparado acerca de las características entre los recursos que le dan aceso a las cortes de casación que caracterizan el modelo ítalo-francesa, la corte mexicana, por medio del amparo de las cortes del common law, por medio del appel. TARUFFo, Michelle, Appeal, cassation, amparo and all that: what and why? En Estudios en homenaje al doctor Héctor Fix-Zamudio en sus treinta años como investigador de ciencias jurídicas (México, 1988), III, p. 2045-2047. En el mismo sentido distinguiendo entre finalidad pública y privada como instrumento teórico para la propuesta de la función o propósito de las cortes supremas, Kerameus, Konstantinos. Corti supreme a confronto: stato dele cose e linee evolutive, en Rivista Trimestrale di Diritto e Procedure Civile, 53 (1999), pp. 145-146.

${ }^{41}$ Jolowicz, John Anthony, The Role of the Supreme Court at the National and International Level. A General Report, en YeSSIOU-FALTSI (editor). Role of the Supreme Court at the National and International. (Thessaloniki, 1998), pp. 47-63.

${ }^{42}$ Jolowicz, cit. (n. 16), pp. 52 s. Por otro lado, la finalidad privada de una corte es satisfecha en la resolución de disputas jurídicas concretas. En relación a este punto, el autor pone desde luego una diferencia relevante: el interés de los litigantes que establece el derecho a recurrir a los tribunales de más alto rango no sirve sólo a fines egoístas, sino también al interés de obtener una respuesta judicial de acuerdo con el derecho. Sin embargo, eso no significa afirmar que la resolución de la disputa jurídica se produce en nombre de la paz social, como una garantía estatal ofrecida a cambio de la autotutela.

${ }^{43}$ SiLVESTRI, cit. (n. 23), p. 106.
} 
importante para caracterizar la naturaleza de los órganos de los tribunales de casación del tipo franco-italiana y española, pero no es exclusiva de estos. También los tribunales que se definen a sí mismos como "tercera instancia" 44 (porque sin duda deciden sobre el fondo de la controversia), como la "Revisiongericht" alemán (aunque con varias reservas en esta categorización desde la reforma del año 2002), tienen una función reactiva de control de legitimidad. Estos, en general, no pueden valorar las pruebas de nuevo, pero verifican si el tribunal de primera instancia aplicó correctamente la ley (y, si no, pronuncian una sentencia sobre el fondo que sustituye a la decisión errónea) ${ }^{45}$. Tradicionalmente puede, sin embargo sostenerse que en los modelos de corte suprema, de casación como de revisión los tribunales tienen (entre otras) la tarea de verificar si el derecho fue aplicado correctamente en la decisión del caso sometido a su examen ${ }^{46}$.

Esta función también es desarrollada por las cortes del sistema de "common law": las cortes supremas de los Estados Unidos e Inglaterra deciden el caso verificando si el derecho ("statute" o "precedent") fue o no aplicado correctamente por el tribunal de instancia inferior. Por lo tanto, queda visible el desempeño de una función reactiva de verificación de la legitimidad de la decisión ${ }^{47}$.

b) Lo público y lo privado en verdad, aparecen como dos caras de una misma moneda ${ }^{48}$. En otras palabras, puede existir una decisión reactiva sin observar el futuro y una decisión proactiva independiente de la violación del derecho. Por otra parte, ambas funciones pueden ser ejercidas en diferentes intensidades ${ }^{49}$. En el caso de la Corte de Casación italiana, por ejemplo, el control de la legitimidad de la decisión en el caso particular parece esencial, porque es la última instancia de justicia del caso. Orientación que es destacada tanto por la redacción actual del art. 111.7

${ }^{44}$ Véanse en detalle: HaHn, Carl (coordinador), Die Gesammten Materialien zur Civilprozeßordnung (Berlin, 1880), I, p. 364; ARENs, Peter, Die Befugnis des Revisionsgerichts zur Entscheidung in der Sache selbst, en AcP., 161 (1962), pp. 177, 179-180.

${ }^{45}$ GotTwald, Peter, Die Revisionsinstanz als TatsacheninstanzBerlin, 1975), pp. 82 s.

${ }^{46}$ TARUfFo, cit (n. 35), p. 16. Las diferencias incluso entre los modelos citados se reducen con las reformas recientes a la casación italiana y su acercamiento a la revisión alemana.

${ }^{47}$ TARUfFo, cit (n. 35), p. 17.

${ }^{48}$ Jolowicz, cit. (41), pp. 59-60. No obstante, parece correcta la relativización que concluye haciendo Taruffo de estas distinciones (funciones públicas y privadas, reactivas y proactivas) que siguen siendo válidas bajo el aspecto analítico, en la medida en que muestran diferentes aspectos del fenómeno, así como porque ni siempre las dos funciones se desarrollan juntas.

${ }^{49}$ JolOwiCZ, cit. (41), p. 17. 
de la Constitución italiana, como por la interpretación que el Tribunal de Justicia, desde 1953, dio al recurso de casación ${ }^{50}$.

\section{LOS RECIENTES CAMBIOS DE PARADIGMAS}

1. No obstante, este modelo concreto de legitimidad de las decisiones judiciales se convierte en sólo un papel secundario de las cortes supremas, cuando el acceso a ellas deja de ser generalizado, es decir, deja de ser un derecho subjetivo para cualquier persona en cualquier proceso. Esto es lo que sucede cuando la interposición de un recurso de casación tiene su admisibilidad condicionada a la aprobación del tribunal inferior y de la propia Corte Suprema. Si esa admisibilidad incluye elementos que podrían trascender al mero interés privado o particular es que para el acceso al máximo tribunal mediante un determinado recurso que condiciona su admisibilidad a determinado requisito termina tiñendo la función misma de esa corte. En este caso, el interés subjetivo del solicitante no es la razón decisiva; para tener acceso a la Corte es necesaria la presencia de un interés "superior", es decir, un interés que se configura como un derecho fundamental que está más allá de la aplicación de la ley en el caso (como ocurre en la Corte Suprema inglesa y en el Revisiongericht de Alemania y Austria) $)^{51}$.

${ }^{50}$ Este punto de vista de la tutela del ius litigatoris, identificable con la tutela de la legalidad, como distinciones de la Corte de Casación italiana es objeto de severas críticas por la doctrina italiana, debido a la crisis de exceso y sobrecarga de recursos y del tratamiento desigual de tutela en la interpretación de la norma jurídica. De acuerdo con Proto Pisani, Andrea. Principio degualianza e ricorso per cassazione, en Revista de Processo, 191 (2011), p. 205-208; el artículo 111, 7, de la Constitución italiana, según el cual "è sempre en ammesso ricorso Casación por violazione di legge", sin embargo, garantiza el derecho de todo ciudadano a acercarse a la Corte de Casación contra la sentencia de otros provimientos decisorios, por razón de violación de norma jurídica, es, sobre todo, un valor, y como todo valor constitucional debe equilibrarse con otros valores constitucionales, en especial los valores de la duración razonable del proceso y de igualdad ante las decisiones. Por lo tanto, la ponderación entre estos valores constitucionales, impone la reestructuración con urgencia del sistema de impugnación civil, con la introducción de un filtro de acceso a la Corte, con el fine de que esta asuma la función pública de uniformización de la jurisprudencia. En la misma dirección: CAPONI, Remo. La modifica dell art. 360, 1 comma, n. 5 c.p.c. [disponible ern www.academia.edu (visitado el 12 de marzo de 2015)]. Sobre el problema de la reforma de la casación véase: TARUfFO, Michele, Una reforma dela Cassazione civile? en Rivista Trimestrale di Diritto e Procedura Civile, 3 (2006), pp. p. 755-786.

${ }^{51}$ Con respecto al acceso a la Corte Suprema de Justicia alemana, el $\$ 543,2$ ZPO., modificado por la reforma que ocurrió en 27 de julio de 2001, prescribió un filtro de admisibilidad, según el cual sólo se permite el aceso ante la Corte Suprema 
2. En este último modelo, la Corte Suprema -admitiendo el recursoverifica si el derecho fue aplicado correctamente en el caso, pero esta ya no es la única y exclusiva función desempeñada por la Corte al examinar el recurso. Su interés en realidad está en definir una orientación uniforme acerca de la interpretación de la norma jurídica, con el fin de que pueda ser aplicada en los casos futuros similares ${ }^{52}$. La función de promoción de la legalidad, tal como era definida por Taruffo, es, tal vez, la principal función de las modernas cortes supremas y es esencialmente proactiva, en la medida en que lo que justifica la apreciación del recurso son factores que se orientan al futuro. Este tipo de decisión puede guiar las decisiones futuras en cuestiones jurídicas de relevancia más allá del individual, lo que comprueba el rol "público" ejercido por los tribunales ${ }^{53}$. Por otro lado, la promoción de la función pública de la Corte Suprema no quiere decir que en la protección de los intereses del particular (el llamado ius litigatoris) se dé menor importancia o quede directamente excluido. Sucede que la correcta aplicación judicial del derecho en la resolución de la controversia jurídica concreta siempre debe garantizarse, en tanto que el Estado está obligado a proporcionar una respuesta judicial adecuada y eficaz a los problemas jurídicos ${ }^{54}$. La función pública y proactiva queda evidente, por lo tanto, cuando: $i$ ) el acceso a la Corte Suprema está sujeta a una selección de los casos ${ }^{55}$; ii) la actividad de la corte se dirige principalmente a producir y gestionar precedentes. La gestión en prospectiva genera criterios sustentables para el tratamiento de casos similares, la posibilidad de cierta disuasión en la litigiosidad a gran

cuando la pregunta trata de derechos fundamentales o importancia, o cuando la evolución del derecho a la tutela de la uniformidad de la jurisprudencia requiere una decisión. De acuerdo con esta definición legislativa, no hay duda en cuanto a la elección de la legislación alemana en la defensa de la función del ius constituciones. Esta opción, que fue confirmada por la Corte Constitucional, que en el juicio de la legitimidad de dicho artículo (sentencia de 1 de agosto de 2004, BVGr 864-03), sostuvo que la Constitución no requiere la provisión de un mecanismo para garantizar el acceso sin restricciones a la impugnación, dejando el legislador libre para disciplinar sobre el sistema de filtro recursal: VV. AA., Le corti supreme in Europa: le regole per lacesso. Ufficio del Massimario della Corte Suprema di Cassazione, pp. 9-10 [disponible en: www.cortedicassazione.it/Documenti/Relazione\%20Corti\%20 Supreme_08.pdf (visitado el 12 de marzo de 2015).

${ }^{52}$ TARUfFo, cit (n. 35), p. 20.

${ }^{53}$ Ibíd., p. 32.

${ }^{54}$ Liebmann, Enrico, A força criativa da jurisprudência e os limites impostos pelo texto da lei en Revista de Processo, 43 (1986), p. 59

${ }^{55}$ Ver detalle de los filtros de acceso en las cortes europeas en Le corti supreme in Europa: le regole per Lacesso, Ufficio del Massimario della Corte Suprema di Cassazione. p. 9-10 [disponible en: www.cortedicassazione.it/Documenti/Relazione $\% 20$ Corti\%20Supreme_08.pdf (visitado el 12 de marzo de 2015)]. 
escala y claro está sienta las bases para que incluso esos criterios puedan mutar si se dan los casos que impongan su cambio total o parcial.

3. Desde esa perspectiva, como advierte Jolowicz, el problema que afecta a las condiciones de trabajo de las cortes supremas es el pequeño número de casos en los cuales hay un auténtico interés público en detrimento de un gran número de casos que requieren la corrección de la decisión por violación de la ley, hecho que inevitablemente sacrifica el papel proactivo de la Corte ${ }^{56}$. La tendencia que se observa en los últimos años, la cual parece ponerse al nivel general, revela que el papel tradicional reactivo de la tutela de la legalidad en los casos concretos dieron espacio para la actuación del papel proactivo en el desarrollo de la ley o mejor de la juridicidad ${ }^{57}$.

\section{EL CRITERIO DE UNIVERSALIDAD COMO SUSTENTO}

a) En efecto, el criterio de la universalidad es justamente la afirmación de que una única respuesta cierta no existe, puesto que sirve como criterio de racionalidad y de justicia formal en la justificación de la elección de una de las respuestas igualmente válidas, por el juez en la resolución de casos, especialmente difíciles. Como dice Marina Gascón, la garantía de la racionalidad, por medio de una respuesta correcta institucionalmente

${ }^{56}$ Jolowicz, cit. (41), p. 60. En resumen, del análisis de la experiencia del derecho comparado, podemos afirmar que son dos las funciones principales que se pueden asignar a una Corte Suprema, una pública, consistente en la preservación de la uniformidad de la jurisprudencia, a través de la creación de precedentes (justicia formal y procedimental), y en el desarrollo del derecho; otra privada, creada bajo la tutela de la corrección de la decisión del caso, a través de la realización de la justicia sustantiva.

${ }^{57}$ Para una visión general sobre el papel asumido por las cortes supremas en el derecho comparado actual, ver: ОTEIZA, Eduardo. A função das cortes supremas na América Latina. História, paradigmas, modelos, contradiçôes e perspectivas, en Revista de Processo, 187 (2010), pp. 181-230; STÜRNER, Rolf. The New Role of Supreme Courts in A Political and Institutional Context from the German Point Of View, en Annuario di Diritto Comparato e di Studi Legislativi (Napoli, 2011), p. 335-358; Lindblom, Henrik. The Role of the Supreme Courts in Scandinavia, en Scadinavian Studies in Law, 39 (2000), pp. 337-349. Ese artículo es una versión actualizada del informe regional presentado en el "Coloquio internacional, de la Asociación Internacional de Derecho Procesal”, que tuvo lugar en Thessaloniki, en el año de 1997, sobre el papel de las cortes supremas, el mismo que originó el informe general de Jolowicz. En la perspectiva del derecho supranacional, véase: Trocker, Nicolò. L'Europa delle corti sovranazionali: una storia di judicial activism tra tutela dei singoli ed integrazione degli ordinamenti giuridici, en Annuario di Diritto Comparato e di Studi Legislativi (Napoli, 2011), pp. 91-128. 
garantizada, se debe precisamente al hecho de que el dominio natural de las reglas está constituido por la discrecionalidad jurídica ${ }^{58}$.

El término "corrección” es "theory-dependent" en tanto puede referir a una adecuación epistémica en tanto verdaderos (corrección fáctica) o bien tener una adecuación axiológica en tanto significar justos (corrección axiológica o bien normativa) ${ }^{59}$. Si tomamos la teoría del discurso, una regla es válida (justificada, correcta) si puede mostrarse, a través del discurso secuencial racional, que ella es aceptable racionalmente por todos los afectados. Este presupuesto es el que se designa como principio de universalización. Siendo así que todos los involucrados en (U) puedan aceptar las consecuencias y efectos principales y colaterales que la observancia universal de la norma acarreará para la satisfacción de los intereses de cada interesado. El Estado de derecho no puede coexistir con razones normativas universalizables distintas que resuelvan el mismo problema de interpretación, clasificación o relevancia jurídica. Esto es así porque la exigencia de universalidad se fundamenta precisamente en la necesidad de igualdad de tratamiento de casos similares, como medida de realización del principio de la justicia formal y de generalidad de las normas jurídi$\operatorname{cas}^{60}$. En ese sentido MacCormick sostiene que el hecho de no ser posible determinar através de una argumentación jurídica racional y razonable (teniendo en cuenta que la coherencia y la consistencia tienen un papel limitado en la interpretación), la solución correcta o definitiva acerca de

${ }^{58}$ En sus palabras: "But the requirement of universalizability is particularly evident when judges have a discretionarily; that is, when no conclusive or peremptory rules exist when solving a specific case; or which is the same, when all of the material available cannot offer the desired right answer [...]. It is due to the fact that the natural domain of the rules is that of legal discretionarily, the rules becomes meaningless where institutionally one right answer is guaranteed": GASCON, Marina. Rationality and (Self) Precedent: Brief Considerations Concerning the Grounding and Implications of the Rule of Self Precedent, en Archiv für rechts-und sozialphilosophie, 33 (2012.), p. 39.

${ }^{59} \mathrm{Cfr}$. Diciotтi, E., Controversie interpretative, pretese di correttezza, giustificazioni, en Pagliatini - Quadri - Sinesio (coordinadores), Scritti in onore di Marco Comporti (Milano, 2018), II, pp. 1103-1134. La idea de la respuesta correcta, por lo tanto, asume el carácter de una meta que debe perseguirse en todo razonamiento jurídico que tenga la intención de ser justo y equitativo, en especial en su dimensión formal. No obstante, si la búsqueda de esta meta a nivel individual, por un lado, asegura la justificación de la decisión tomada por el juez o tribunal, por el otro, nos lleva al problema de convivir con diferentes razones universalizables. Ya resulta complejo demarcar a qué se refiere uno cuando habla de "corrección de la decisión"

${ }^{60}$ Aunque criticable y débil en algunos argumentos, cfr. WASSERSTROM, Richard, The Judicial Decision-Toward a Theory of Legal Justification (Standford, 1961), pp. 81-83. 
los problemas más controversos en el derecho, no deja otra opción sino la de aceptar la fuerza de una opinión investida de autoridad. Aclarando que ello no significa sostener que dicha opinión sea para todos los fines autocertificadora y "racionalmente incorregible" ${ }^{61}$. Razón por la cual, entonces, se hace necesario e inevitable el trabajo de investigación sobre la forma como las cortes supremas están decidiendo, o sea, acerca de la calidad de la argumentación jurídica desarrollada y como las razones usadas como justificación son coherentes y consistentes con el sistema jurídico ${ }^{62}$. La institución de un precedente vertical, cuya aplicación es obligatoria para los tribunales inferiores, podría entonces contradecir el requisito del criterio de la universalidad en la justificación de sus decisiones (en tanto materia de justicia formal), ya que el razonamiento jurídico estaría limitado por los precedentes del tribunal superior, lo que limitaría la "libertad" e independencia decisional (independencia interna) de los tribunales inferiores $^{63}$. Ello claro está si se considera la independencia interna en

${ }^{61}$ MaCCormick, cit. (n. 12), pp. 278 s.

${ }^{62}$ Interesante es hacer una aclaración al respecto de la observación hecha por Andrés de la Oliva, que afirma, en la misma dirección del razonamiento adoptado por Michele Taruffo, que la convergencia entre los sistemas jurídicos de civil law y common law, consistente, fundamentalmente, en el uso vinculante de los precedentes, sólo se sustenta y vale en la medida en que "es un precedente dotado de autoridad intrínseca, basada en la calidad del análisis y en la racionalidade y buen sentido de la justicia y de la equidad que se aprecia en la respuesta judicial al problema jurídico de que se trate": DE LA OlIVA SANTOS, Andrés, Un modelo de casación civil eficaz para el tribunal supremo de España, en Annuario di Diritto Comparato e di Studi Legislativi (Napoli, 2011), p. 273.

${ }^{63}$ MacCormick, Neil, Why Cases Have Rationes and What These are? en GoldSTEIN (coordinador), Precedent in Law (Oxford, 1987), pp. 155-182; quien, en la p. 160, sostiene: "It is a matter of formal justice in the sense in which it calls for like decisions in like cases- and unlike ones in unlike cases". Cfr. Siltala, Raimo, $A$ Theory of Precedent Oxford - Portland, 2000), pp. 121-148. Véase igualmente: PostemA Gerald, "A Similibus ad Similia.2 Analogical Thinkingin Law, en EdLIN, D. (coordinador), Common Law Theory (Cambridge, 2007), pp. 27-50. Sobre la importancia de la independencia judicial en el Estado democrático de derecho véase: SHETreET, Shimon, Creating a Culture of Judicial Independence, en ShetreEt, S. - Forsyth, Ch. (coordinadores), The Culture of Judicial Independence. Conceptual Fundations and Practical Challenges (Leiden, 2012), pp. 17-67, esp. 44-45; cfr. GERHARDT, Michael, The Power of Precedent Oxford, 2008), pp. 172-176; STORME, Marcel, Independence of the Judiciary: The European Perspective, en Shetreet, S. - Forsyth, Ch. (coordinadores), The Culture of Judicial Independence. Conceptual Fundations and Practical Challenges (Leiden, 2012), 17-67, esp. 44-45; García, José F. - Verdugo, Sergio, Activismo judicial en Chile. ¿Hacia el gobierno de los jueces? (Santiago, 2013), pp. 149-149. Conviene tener presente la noción y los ejemplos de lo que se denomina "activismo judicial", que no es identificable con el precedente. 
términos incluso abstractos y generales de modo que un juez que no debe decidir un caso concreto en relación al cual existe un precedente, podría perfectamente sostener que goza de libertad absoluta para decidir como quisiera si se presentara un caso como el ante descrito en el ámbito de su competencia. Pero podría replicarse que esta objeción no es correcta, porque el deber del juez es decidir de acuerdo a derecho, y, si el sentido y alcance del derecho para ese (esos) supuestos esto ya ha sido definido por el vértice, su deber es de seguirlos ya que como juez en ese caso particular integra el engranaje de gestión tenido en cuenta al momento en que en prospectiva se decidió en tal sentido. Lo decidido en un sentido con relación a un caso que se repite minimiza el riesgo de error en la nueva confrontación con la disputa a ser resuelta ${ }^{64}$. Sólo en los casos en que exista un espacio de discrecionalidad que derrote esa interpretación y aplicación que constituye el precedente de modo que en la resolución del problema jurídico propone la práctica de una justificación universalizable, como en las situaciones de "distinguishing" 65

b) Por otra parte, la Corte Suprema tiene que cumplir con el requisito de universalidad en la justificación de sus decisiones judiciales, para asegurar que, al definir la "respuesta correcta" (y final) que revestirá la autoridad que vinculará todos los demás tribunales y jueces, está actuando de manera racional e igualitaria ${ }^{66}$. Claro que el precedente horizontal plantea desafíos (en el caso de tribunales superiores que funcionan en salas o cámaras especializadas), pero consideramos que comenzando por lo más complejo de aceptar que es el supuesto vertical, aquel resulta fácilmente abordable. Pero una Corte Suprema que no respeta sus propios precedentes, además de actuar incorrectamente, cancela la legitimidad de sus razones normativas $^{67}$. La razón de la autoridad de una decisión en tanto precedente no la da el hecho que sea pronunciada por el máximo tribunal, sino que esa decisión tenga la fuerza legitimante de razones suficientes ${ }^{68}$.

${ }^{64}$ AleXander, Larry - SHeRwin, Emily, Desmystiying Legal Reasoning (Cambridge, 2008), pp. 59-61.

${ }^{65}$ Duxbury, Neil, The Nature and Authority of Precedent Cambridge, 2008), pp. 58 ss., 116 ss.

${ }^{66}$ Fernández, Patricio - Ponzetto, Giacomo, "Stare decisis: Rhetoric and Substance, en Journal of Law, Economics, and Organization, 28 (2012) 2, pp 313-36; SweEt, Alex Stone, Governing with Judges (Oxford, 2000), p. 146.

${ }^{67}$ En relación a la justificación de los precedentes horizontales véase AlEXANDER, Larry - SHERWIN, Emily, Judges as Rulemakers, en EDLIN, D. (coordinador), Common Law Theory (Cambridge, 2007), pp. 27-50.

${ }^{68}$ Idea similar es presentada por SILVESTRI, Elisabetta, Corti supreme europee: acceso, filtri e selezione, en Le Corti Supreme. Atti del convegno svoltosi a Perugia il 5-6 
1. La decisión vinculante en prospectiva.

a) Es cierto que toda disputa jurídica surge de un problema que se ha producido en el caso concreto y, por consiguiente, la función de resolución de conflictos es esencial. Por lo tanto, el desempeño de la función privada es ínsito al ejercicio de la función adjudicativa. Por otra parte, el ejercicio de la función pública, es decir, la dimensión de la creación de normas jurídicas, también se ejerce por la corte suprema cuando decide una disputa jurídica particular. Así es que explica el significado atribuido a las normas controvertidas, la aplicación y las consecuencias jurídicas resultantes. Eso porque a los tribunales es impuesto el deber de decidir (inexcusabilidad), incluso en el caso de omisión legislativa, contexto en que deberá recurrir a la analogía, a las costumbres y a los principios generales del derecho ${ }^{69}$. La corte suprema, por lo tanto, siempre ejercerá tanto la función pública como la privada, ya que ambas están presentes en la función básica de un tribunal, es decir, la de resolución de disputas jurídicas concretas ${ }^{70}$.

maggio 2000 (Milano, 2001), p. 110, con fundamento en las enseñanzas de Piero Calamandrei, para reconstruir el significado de la función pública de la corte suprema como reguladora judicial de la uniformidad de la interpretación jurisprudencial. De acuerdo con la profesora italiana: "Alla corte, isomma, spetta il monopolio di enunciare la única interpretazione ufficialmente coforme alla legge, interpretazione che appare nello Stato come la única interpreazione della legge, di fronte alla quale tutte le interpretazioni giuridiche da essa discordanti sono dichiarate false ed illegali. [...] Si potrebbe parlare di funzione pubblica della corte suprema solo a condizione che il suo operato e, più precisamente, il controllo che essa esercita sulle decisione dei giudici inferiori, siano diretti a realizzare innanzi tutto il valore della certezza uniforme dell'interpretazione della legge". Corti supreme europee: acceso, filtri e selezione. De otro lado, TARUfFo, Michele, Una reforma della Cassazione civile? en Rivista Trimestrale di Diritto e Procedura Civile. (2006) 3, p. 761, afirma que la función de uniformidad de la jurisprudencia aparece de forma evidente en la mayor parte de las modernas cortes supremas europeas, una vez que su principal función consiste en el establecimiento de precedentes, por medio de la definición de la interpretación correcta de la ley. En resumen: los tribunales de instancia superior, por su posición de vértice en el sistema jurídico deben actuar como auténticos reguladores de la uniformidad de la interpretación judicial. Su colocación en la cúspide del poder judicial implica el poder y el deber de controlar la actividad de interpretación de los jueces inferiores.

${ }^{69}$ Maultzsch, cit. (n. 5), pp. 291 s.

${ }^{70}$ BaraK, Aharon, The Judges in a Democracy (Princeton, 2006), pp. 116-132. El problema, entonces, para definir la función de una Corte Suprema y su perfil de acuerdo con el diseño (estructural y evaluativo) propuesto por el ordenamiento jurídico, se transfiere al campo de cómo una disputa jurídica es resuelta. En otras palabras, cómo el proceso de toma de decisiones se desarrolla en el cumplimiento de la finalidad pública de producción de normas jurídicas 
b) $\mathrm{Al}$ respecto, hacemos uso de la explicación propuesta por Melvin Eisenberg. Para el autor, dos modelos son posibles en el papel de la corte para establecer normas jurídicas. En el primero, llamado "by-product model", las proposiciones normativas se crean de forma incidental e instrumental, demostrando ser un subproducto de la resolución de disputas particulares. La justificación en la formulación de tales proposiciones se da sólo en la medida necesaria para resolver el litigio, no importa su efecto futuro. El segundo modelo, designado como "enrichment model", a su vez, trata el establecimiento de normas jurídicas como el objetivo principal, asumiendo la corte posición de un regulador de las conductas sociales; es decir, no obstante el derecho desarrolle el derecho a través de la resolución de casos concretos, lo hace de acuerdo con la creación de una regla general que tenga el papel de referencia futura ${ }^{71}$. Eisenberg destaca que la toma de posición por uno de los modelos de tribunal se convierte en imprescindible, en tanto pueda reflejar directamente la forma como las decisiones son formuladas y publicadas, especialmente, en la expectativa de los ciudadanos ${ }^{72}$. La creación de normas jurídicas desde la perspectiva del "subproduct model" se produce secundariamente. Su objetivo principal es revisar las decisiones y lograr la justicia del caso concreto, hecho que descuida de otros objetivos de carácter claramente público, tales como la unificación de la jurisprudencia y la definición de los derechos, sirviendo, en consecuencia, a los propósitos de los tribunales de revisión judicial (de tercera instancia) $)^{73}$.

c) Es necesario fijarse, sin embargo, en la importancia que el caso concreto asume en el cumplimiento del propósito público. Todo precedente

${ }^{71}$ EISENBERG, cit. (n. 9), pp. 5-7. Bien vistas las cosas, los modelos propuestos por Eisenberg siguen la misma línea de razonamiento y los objetivos de los modelos para la justificación de las decisiones propuestas por el universalismo y el particularismo, con la diferencia de que el subproduct model, a pesar de estar centrado en la resolución de conflictos particulares, se basa en normas y es consciente del resultado, aunque instrumental, de creación de esas.

${ }^{72}$ AleXANDer, Larry - Sherwin, Emily, cit. (n. 67), pp. 64-67.

${ }^{73} \mathrm{El}$ argumento de EISENBERG, cit. (n. 9), p. 7: “The function of resolving disputes faces toward the parties and the past. The function of enriching the supply of legal rules faces toward the general society and the future. As I will show, a major objective of the institutional principles of common law adjudication is to reconcile the tensions that may arise out of the difference in orientation between these two functions". Sin embargo, tales fines no justifican la creación y el mantenimiento de una Corte Suprema que deba asumir una postura inversa: la de definición de la "respuesta correcta" en el ordenamiento jurídico, es decir, el alcance y la interpretación de la norma de derecho, a través de la creación de precedente. Es por eso que podemos decir que el enrichment model es el modelo que está en conformidad con el requisito del principio de universalidad y comprometido con los valores del Estado de derecho. 
es creado a partir de un conjunto de hechos y argumentos particulares discutidos $^{74}$. La razón universalizable que justifica la decisión es tomada desde un espacio de juicio factible, en que los hechos y los argumentos jurídicos son definidos para, por un lado, facilitar y aclarar el elemento normativo vinculante para las decisiones futuras, $y$, por otro, permitir el desarrollo del proprio precedente, sea mediante la creación de nuevos universales, sea con su propio ámbito de aplicación ${ }^{75}$. La proyección hacia el futuro esperado de los precedentes y la igualdad de tratamiento de los casos, a través de la unificación de la jurisprudencia, sólo puede lograrse con una cuenta de justificación universalizable de la decisión judicial, teoría ésta que no es más que una exigencia teórica y práctica de cualquier Estado que desee ser conforme al Derecho ${ }^{76}$.

d) Aquí debe hacerse una advertencia. La proyección esperada del precedente hacia el futuro, la función proactiva, como la denominada por Taruffo, no representa un abandono de las decisiones del pasado y de la función reactiva. La coerción de la justicia formal implica un deber

${ }^{74}$ Duxbury, cit. (n. 65), pp. 67-76.

${ }^{75}$ Taruffo, Michele, Precedente e giurisprudenza, en Rivista Trimestrale di Diritto e Procedura Civile, 61 (2007) 3, p. 796, con fundamento en la teoría de la razón normativa universalizable propuesta por MacCormick, destaca la importancia que el caso particular adquiere para la formación del precedente, puesto que este es limitado a una "fattispecie" específica. Según el professor de Pavia: "Esso attiene alla circonstanza che poiché il precedente è sempre una decisione relativa ad un caso particolare , ocorre che il significato della regola giuridica usata come criterio di decisione venga 'concretizzato' per riferilo alla soluzione del caso particolare: il precedente no se comprende se l'interpretazione della norma che in esso è stata applicatanon viene conessa direttamente con la fattispecie concreta che è stata decisa".

${ }^{76}$ TARUfFo, cit. (n. 78), p. 25 s. "Va inoltre considerato che la nomofilachia che si realiza per mezzo delle precedente è evidentemente rivolta verso il futuro: vero è, infatti, che la decisione che stabilisce il precedente risolve un caso passato, mas si trata di una decisone che si rivolge verso il futuro perché si propone come un modelo per decisioni sucessive". TARUFFO, Michele, Le corti supreme europee: acceso, filtri e selezione, en Le Corti Supreme: atti del convegno svoltosi a Perugia il 5-6 maggio 2000 (Milano: 2001), pp. 95-104. En ese último paper, Taruffo, para justificar la función pública y las cortes supremas, por medio de la creación de precedentes, se vale de la teoría general de la interpretación defendida por MacCormick sobre el criterio de la universalidad. En efecto, eso es relevante para el adecuado ejercicio del orden público por la Corte Suprema, en la medida que el caso concreto es que dará el "tono" para la percepción de cuáles problemas ya han sido resueltos o no por la Corte. Dicho eso, aclaramos el problema de cómo la finalidad pública es realizada en el razonamiento jurídico emprendido por las cortes supremas. Como argumenta Taruffo, el modo de llevar a cabo la tarea de creación y evolución del derecho por las cortes supremas se ha apoyado en la eficacia de los precedentes esperados de sus decisiones, porque es este que proyecta hacia el futuro lo que dice la Corte. 
de doble sentido, es decir, la obligación que el juez tiene de tratar casos similares de forma similar implica el deber de decidir el caso de hoy con las razones que puedan ser adoptadas en las futuras decisiones, en la misma medida que implica el deber de llevar en consideración las decisiones anteriores tomadas en el pasado ${ }^{77}$. En esa línea, MacCormick afirma que las dos incumbencias adhieren al principio de justicia formal y claro que quien desee que exista una concordancia entre el deber de los jueces de acatar el principio de justicia formal se compromete con ambas. ${ }^{78}$ Por lo tanto, las cortes supremas sólo podrán lograr su finalidad pública de creación de una jurisprudencia uniforme y prospectiva si los efectos de sus decisiones obligaren al proceso de toma de decisiones más allá del caso concreto y de los jueces sucesivo, sean de igual jerarquía, sean de jurisdicción inferior (estos con más razón).

2. La razón de lo universable (generalizable) en prospectiva: tomando los precedentes en serio.

a) En esta perspectiva, una cuestión que asume gran importancia es la del comportamiento del juez posterior (siguiente), que es quien determina cómo las decisiones pasadas se deben aplicar a estos casos ${ }^{79}$. Jeremy Waldron expone el problema de esta manera: cuando un caso similar al que decida el tribunal superior llega en las manos de un juez posterior (ya sea de primer grado o incluso un tribunal de segunda instancia), ¿`cuál es comportamiento que éste debe tomar? Debe manejar el caso de la misma manera como lo hizo el juez predecesor -es decir, debido a que el derecho vigente no ha regulado directamente o explícitamente el problema jurídico, resolvió el caso a partir de la creación de una proposición normativa universalizable-; o, por lo contrario, ¿¿debe tomar el caso como un problema

${ }^{77}$ MacCormick, Neil. Legal Reasoning and Legal Theory (New York, 1978), p. 74.

${ }^{78}$ MacCormicK, cit. (n. 77), p. 75. "Trite as it is that the requirements of formal justice establish at least a presumptive reason for following relevant precedents, it is no less true, although less commonly observed, that these requirements impose forward looking as well as backward-looking constraints on the decision of litigated disputes".

${ }^{79}$ Fernández, Patricio - Ponzetto, Giacomo , "Stare decisis: Rhetoric and substance, en Journal of Law, Economics, and Organization, 28 (2012) 12, pp. 313-36. La razón normativa universalizable debe servir como criterio en la justificación de las opciones interpretativas abiertas al juez en la resolución de los casos concretos. Por lo tanto, corresponde a la Corte Suprema definir la razón justificadora universal que debe prevalecer como correcta, y, consecuentemente, es responsable por la creación de un precedente que servirá como referencia para los casos futuros. 
que ya tiene una regla aplicable en el sistema, debiendo identificarla y articularla en su resolución? ¿Cómo el tribunal posterior (o juez) deberá considerar la razón normativa universalizable? ${ }^{80}$ De acuerdo con Waldron, el criterio de universalidad (o "generalidad" como llama), al exigir que los jueces trabajen conjuntamente en la tarea de definición de las normas jurídicas, como miembros de un cuerpo coherente (no como la suma de las voluntades individuales), asume función basilar en la construcción del Estado de derecho ${ }^{81}$.

b) La negativa del uso del precedente por los jueces en la justificación de las decisiones judiciales, después de todo, implica un cambio en la naturaleza de la motivación de la sentencia anterior, en el caso presente, la Corte Suprema, que deja de ser una razón universalizable para ser un argumento por analogía ${ }^{82}$. Y aquí algunas aclaraciones deben ser hechas. El argumento por analogía y el argumento por precedente no son faces de un mismo fenómeno. Como explica Frederick Schauer, es común que equiparaciones sean hechas entre ambos argumentos, ya que la analogía es prevista en la ley y generalmente es utilizada como referencia para los argumentos tomados en las decisiones ${ }^{83}$. Sin embargo, esta clasificación,

${ }^{80}$ WaLdron, Jeremy, "Stare decisis and the Rule of Law: a layered approach, en NYU School of Law [disponible en: http://ssrn.com/abstract=1942557. p. 25 (visitado el 12 de marzo de 2015)]. Como ya se sostuvo, el juez sucesivo frente a un precedente formado por la Corte Suprema o de la cual haga parte deberá, como acto de responsabilidad personal, tratar el precedente como expresión de una norma positiva y no como una mera referencia disuasiva. Este comportamiento es lo que el Estado de derecho exige: el respecto por los precedentes como verdadera norma jurídica del sistema. Esto revela por qué el criterio de universalidad en el precedente debe ser tomado en serio por los distintos jueces y en las sentencias posteriores.

${ }^{81}$ WALDRON, cit. (n. 80), pp. 23-26. En otras palabras: cuando la corte sucesivamente resuelve la cuestión legal en el caso $x$ precedente, basada en otras razones, las cuales entiende como correctas y pertinentes para la adecuada resolución de la controversia, y desconsidera el efecto de constricción del precedente, se rompe la unidad del orden jurídico, creando decisiones incoherentes acerca de los mismos problemas jurídicos, aunque el resultado concreto para la parte sea igual aquél que se obtendría si la razón universalizable establecido hubiera sido reafirmada. Por ese motivo, en la situación del juez sucesivo, la proposición normativa universalizable debe permanecer íntegra y ser utilizada como justificación para la resolución del caso concreto. Sólo mediante la adopción de esta postura por el juez sucesivo es que la justicia formal efectivamente termina su ciclo, con el tratamiento de los casos similares por el intermedio de la igualdad, y el principio del Estado de derecho se realiza.

${ }^{82}$ Acerca del papel del argumento por analogía en el razonamiento jurídico, MaCCORMicK, cit. (n. 77), pp. 205-213.

${ }^{83}$ Schauer, Frederick, Why Precedent in Law (And Elsewhere) Is Not Totally (Or 
no obstante comprensible, es un grave error, una vez que ignora diferencias sustanciales. El argumento por analogía se utiliza en la justificación como razón de refuerzo para la verdadera comprensión del juez, como un ejemplo, y no como un criterio de restricción en su razonamiento ${ }^{84}$. En el razonamiento analógico, la decisión anterior es tomada como ejemplo, en el cual el juez identifica las similitudes entre los casos y trata de explicar en su justificación la necesidad de adoptar la misma conclusión ${ }^{85}$. Por lo tanto, si existe un caso particular que ya fue decidido por una Corte Suprema o mismo por el propio juez, no hay una "elección”, es decir, una opción argumentativa, para el juez sucesivo decidir de la misma manera, sino un deber $^{86}$. Esta es la idea de los precedentes: tomarse como razón normativa para la decisión, mismo cuando el juez sucesivo esté en desacuerdo con las razones sustantivas ${ }^{87}$.

Por supuesto que la idea de uso de precedentes no implica un régimen jurídico autoritario y pétreo. Por obvio que el juez siguiente podrá excluir la razón universalizable que se le impone, pero, para eso, debe ofrecer buenas razones, las cuales deben demostrar que el caso actual no es relativo al mismo problema o que tiene hechos relevantes que lo distinguen o que requiere tratamiento jurídico diferente, o incluso que la decisión es un precedente equivocado. Se trata aquí de las técnicas de "distinguishing" y "overruling", cuya función principal es permitir la oxigenación del sistema y el desarrollo del derecho judicial ${ }^{88}$. "Es decir, para ampliar o

Even Substantially) About Analogy. (August 2007) KSG Working Paper n. RWP07036 [disponible en http://ssrn.com/abstract=1007001 (visitado el 12 de marzo de 2015)

${ }^{84}$ Maultzsch, cit. (n. 5), pp. 24-26.

${ }^{85}$ SChauer, cit. (n. 83), p. 7. Es decir, el juez encuentra atractivo el argumento del caso anterior e intenta convencerse de las razones adoptadas. Sin embargo, el argumento anterior es una restricción impuesta en el razonamiento que requiere la toma de decisiones de acuerdo con la adoptada anteriormente.

${ }^{86}$ En detalle mayores razones y efectos de aplicación del universalismo para la sustentación de legitimidad de los precedentes véase: Pereira, Paula Pessoa, Legitimidade dos precedentes: a universabilidade das decisões do STJ. (São Paulo, 2014), passim. Mejor explicando: argumento por analogía implica seleccionar una fuente análoga, que no es necesariamente un caso decidido previamente, y sirve como elemento persuasivo y no de corrección de la justificación; ya el argumento por precedente, no es una cuestión de elección, sino verdadera restricción en la justificación.

${ }^{87}$ SCHAUER, Frederick, Precedent, en Stanford Law Review, 571 (1987) pp. 16-20. Las virtudes del precedente acompañan los principales argumentos que Schauer usa para la toma de decisiones con fundamento en las reglas.

${ }^{88}$ Para una visión comparada sobre el precedente judicial MACCORMICK, Neil Summers, R., Interpreting Precedents: A comparative Study (Aldershot, 1997), passim, esp. 531-551. No se defiende aquí la pretensión de que el Poder Judicial sea un 
reafirmar una regla o principio de derecho que cubre, o para mostrar que cubre las nuevas situaciones, tales como las que Joseph Raz llama como casos no-regulados" 89 .

\section{EL PRECEDENTE Y LA GESTIÓN DE PROSPECTIVA EN LAS LAS CORTES SUPREMAS DE BRASIL Y CHILE}

Corresponde ahora examinar a las "cortes supremas brasileña y a la chilena" en su comportamiento en relación a todo lo expuesto.

\section{Superior Tribunal de Justiça (STJ) brasileño}

a) En el orden normativo constitucional brasileño, el tribunal que asume la posición de vértice en la jurisdicción ordinaria es el "Superior Tribunal de Justiça". Entre las principales atribuciones que le son conferidas por la Constitución Federal, en el art. 105, III, está la de resolver, en última instancia, las cuestiones jurídicas relativas a la interpretación de las leyes federales infraconstitucionales ${ }^{90}$.

Prescribe el art. 105, III, de la Constitución, que al "Superior Tribunal de Justiça” compete juzgar, en recurso especial, los casos resueltos por los Tribunales de Justicia de las provincias o por los Tribunales Regionales Federales cuando, en única o última instancia: $i$ ) negar validez o contrariar leyes federales o tratados; ii) juzgar válido acto de gobierno legal impugnada frente a la ley federal; o, incluso iii) dar a la ley federal una interpretación divergente de aquella atribuida por otro tribunal. Esa disposición constitucional revela el propósito público de la Corte, consistente en proporcionar la interpretación uniforme del derecho, es decir, de las normas jurídicas,

órgano con la sabiduría de Salomón, que no juzga equivocadamente. La cuestión de la decisión equivocada, por lo tanto, es de vital importancia, tanto para reconocer los límites de la razón argumentativa como para llamar la atención a las necesidades de corrección futura.

${ }^{89}$ MACCORMicK, cit. (n. 12) p. 207. Es interesante señalar que en los casos en que los precedentes no sirven, sea por haber circunstancias o hechos particulares que los distinguen, sea por cualquier otra razón, la decisión precedente actúa como un argumento por analogía. Esto porque el juez debe demostrar que, aunque el caso sea distinto, aquella razón universalizable puede adoptarse con algunos ajustes, operación que favorece la expansión y la contracción de los precedentes. Las analogías son, por tanto, fundamental para el desarrollo del derecho.

${ }^{90}$ No se desconoce aquí que el constituyente ha conferido diversas atribuiciones al Supremo Tribunal de Justicia en el artículo 105 de la Constitución Federal. Sin embargo, eso no es suficiente para apartar el reconocimiento de que su principal función dentro del orden institucional brasileño es el ser una verdadera corte de definición de derechos, o sea, de creación de precedentes. 
garantizando unidad al derecho objetivo federal y el respeto al límite de divergencia judicial que pueda existir ${ }^{91}$.

Sin embargo, debemos darnos cuenta de que la norma constitucional dice muy poco al prever que compete al Supremo Tribunal de Justicia asegurar que las decisiones que "contradicen a la ley o dan a ella una interpretación divergente" no pueden prevalecer en el ordenamiento jurídico. Como argumenta Luiz Guilherme Marinoni, "o texto constitucional, lido em sua dimensão literal, fez prevalecer o costume de se interpor recurso especial alegando-se, simplesmente, que a decisão contrariou a lei federal", contexto práctico y teórico que" impediu à Corte de exercer de forma adequada, até hoje, a sua missão constitucional"'

b) Así, si al Supremo Tribunal de Justicia compete la función propria de una corte suprema, que es garantizar la uniformidad de la jurisprudencia como un elemento indispensable para el ejercicio efectivo del derecho fundamental a la igualdad ante el derecho, el acceso a la corte debe darse por razones compatibles con los valores protegidos por ella. El Supremo Tribunal de Justicia debe dedicarse a resolver sólo recursos especiales interpuestos frente a decisiones que se ponen en dirección contraria a la jurisprudencia establecida por el proprio Tribuna ${ }^{93}$ o cuando no exista

${ }^{91}$ Esa concepción de finalidad pública como fin del Superior Tribunal de Justiça no es una novedad y fue reconocida en la resolución de algunos casos concretos, pero el problema de la práctica del tribunal reside exactamente en eso: en el hecho de que la percepción de la función de la corte de precedentes es de algunos ministros y no del órgano, o sea, adoptada por el plenario en sus decisiones. Es por ello que la jurisprudencia está marcada por profundas y constantes inseguridad. En relación a ello es importante y explicativo el voto-vista pronunciado por el Min. Humberto Gomes en el proceso AgRg 382.736-SC: "O STJ existe e foi criado para dizer o que é a lei infraconstitucional. Ele foi concebido como condutor dos tribunais e dos cidadãos. Bem por isso, a Corte Especial proclamou que: 'Processual -STJ- Jurisprudência -Necessidade de que seja observada. O STJ foi concebido para um escopo especial: orientar a aplicação da lei federal e unificar-lhe a interpretação, em todo o Brasil. Se assim ocorre, é necessário que sua jurisprudência seja observada, para se manter firme e coerente. Assim sempre ocorreu em relação ao STF, de quem o STJ é sucessor, nesse mister. Em verdade, o Poder Judiciário mantém sagrado compromisso com a justiça e a segurança. Se deixarmos que nossa jurisprudência varie ao sabor das convicçōes pessoais, estaremos prestando um desserviço a nossas instituiçõoes. Se nós -os integrantes da Corte- não observarmos as decisões que ajudamos a formar, estaremos dando sinal para que os demais órgãos judiciários façam o mesmo. Estou certo de que, em acontecendo isso, perde sentido a existência de nossa Corte. Melhor será extingui-la' (AEREsp 228432)".

${ }^{92}$ MARINONI, Luiz Guilherme, O STJ enquanto corte de precedentes: recompreensão do sistema processual da corte suprema. (2a edición, São Paulo, 2014), passim.

${ }^{93}$ Ese modelo procesal de acceso a la Corte Suprema fue tomado del propuesto 
una doctrina judicial (leer: un stock de razones universalizables de normas jurídicas) ya producida por el Supremo Tribunal de Justicia acerca de las leyes que aún no han sido objetos de análisis y interpretación. ${ }^{94} \mathrm{El}$ nuevo diseño institucional para el recurso especial privilegia notablemente la prevalencia del ius constitucions en vez de ius litigatoris, en la medida que deja claro que el ciudadano no tiene el derecho subjetivo ilimitado de revisión de su caso particular, sino que ello será configurado como un derecho cuando se está realmente frente a la posible infracción de la norma jurídica ya fijada por el Tribunal en sus precedentes o en las hipótesis de una "ley nueva" o divergencia jurisprudencial ${ }^{95}$. En sentido estricto, asignar amplia función de revisión de los casos a la Corte Suprema significa desfavorecer el trabajo de los tribunales de justicia y de los tribunales regionales federales, que tienen el deber de reexaminar la cuestión de hecho, debido a la amplia devolutividad que tiene el recurso de apelación ${ }^{96}$, en razón de la función reactiva y de la corrección de decisión que se les compete ${ }^{97}$.

por Andrés de la Oliva Santos para el juicio de casación del Tribunal Supremo español, propuesta esa que coincide con la que fue adoptada por el artículo 447, de la nueva Ley de Enjuiciamiento civil de España. Según el autor: "el Tribunal Supremo se dedica en España a resolver recursos de casación por infracción de leyes sustantivas (sin revisión de los hechos ni de presuntas infracciones de leyes procesales) siempre que concurra un interés general determinado por la necesidad de establecer doctrina jurídica interpretativa de las fuentes del Derecho dotada de especial autoridad. Ese interés general, concretamente, el interés casacional, debería prevalecer absolutamente sobre el ius litigatoris y se consideraría existente, no por arbitrio del mismo Tribunal Supremo, sino por la oposición de la sentencia recorrida a doctrina jurisprudencial del mismo tribunal, por la existencia de jurisprudencia contradictoria de los tribunales de segunda instancia o por la inexistencia de doctrina autorizada sobre normas y preceptos materialmente nuevos, al margen de la summa gravaminis de los casos": De la Oliva Santos, Andrés, cit. (n. 62), pp. 277-279.

${ }^{94}$ Puede verse Barbosa Moreira. José Carlos, Comentários ao Código de Processo Civil (15a edición, Rio de Janeiro, 2009), pp. 592-594.

${ }^{95}$ Barbosa Moreira, cit. (n. 94), pp. 593-594.

${ }^{96} \mathrm{Cfr}$. lo sostenido por CAPPELletTI, Mauro, Dictamen iconoclastico sobre la reforma del processo civil italiano, en Proceso, ideologías, sociedad (traducción de Santiago Santís Melendo y Tomás A. Banzhaf, Buenos Aires, 1980), pp. 273-284; o lo ya sostenido por DeNTI, Vittorio, Riforma o controriforma del processo civile? Un progetto per la giustizia civile, en Rivista di Dirittto Processuale, 2a serie, 23 (1970), p p. 434-443. En el mismo sentido, Mitidiero, Daniel. Por uma reforma da justiça civil no Brasil., en Revista de Processo, 199 (2011), pp. 83-99.

${ }^{97} \mathrm{La}$ reciente reforma de 2015 al Código brasileño incluyó el siguiente artículo 926 en el CPC.: "Os tribunais devem uniformizar sua jurisprudência e mantê-la estável, integra e coerente. I $\$ 1$. Na forma estabelecida e segundo os pressupostos fixados no regimento interno, os tribunais editarão enunciados de súmula correspondentes a sua jurisprudência dominante./ $\$ 2$. Ao editar enunciados de súmula, os tribunais devem ater-se 


\section{La Corte Suprema de Chile.}

a) Chile ha sido tradicionalmente un país conservador de sus tradiciones y extremadamente legalista (cuando no incluso sobre la norma constitucional y tratados internacionales de derechos humanos). Tal cual lo describe R. Tavolari ${ }^{98}$ se caracterizó por resistirse a los cambios y la innovación. Consideramos que no es una excepción la resistencia a la influencia del derecho comparado en materia procesal civil y en lo que al rol de la Corte Suprema y los recursos de acceso a ella se refiere. Conviene en esta introducción al modelo chileno incorporar lo sostenido ya hace algunos años por $\mathrm{D}$. Accatino, creemos sigue aún vigente: "Es probable que la primera impresión que provoque hablar de precedente judicial en el contexto de la cultura jurídica chilena sea de asombro o de sospecha. Hemos sido formados como juristas bajo la creencia que la identidad de nuestro sistema legal descansa en alguna (importante) medida en la exclusión de un efecto general y vinculante de las decisiones anteriores de los tribunales de justicia [...]" ${ }^{\prime 99}$. Curiosamente existen mecanimos en

às circunstâncias fáticas dos precedentes que motivaram sua criação”. Por su lado, un artículo 927 dispuso: "Os juízes e os tribunais observarão:/ I. as decisões do Supremo Tribunal Federal em controle concentrado de constitucionalidade;/ II. os enunciados de súmula vinculante;/ III. os acórdãos em incidente de assunção de competência ou de resolução de demandas repetitivas e em julgamento de recursos extraordinário e especial repetitivos;/ IV. os enunciados das súmulas do Supremo Tribunal Federal em matéria constitucional e do Superior Tribunal de Justiça em matéria infraconstitucional;/ V. a orientação do plenário ou do órgão especial aos quais estiverem vinculados. I $\$ 1$. Os juizes $e$ os tribunais observarão o disposto no art. 10 e no art. 489, \ 10 , quando decidirem com fundamento neste artigo./ $\$ 2$. A alteração de tese jurídica adotada em enunciado de súmula ou em julgamento de casos repetitivos poderá ser precedida de audiências públicas e da participação de pessoas, órgãos ou entidades que possam contribuir para a rediscussão da tese./ \$3. Na hipótese de alteração de jurisprudência dominante do Supremo Tribunal Federal e dos tribunais superiores ou daquela oriunda de julgamento de casos repetitivos, pode haver modulação dos efeitos da alteração no interesse social e no da segurança jurídica.I $\$ 4$. A modificação de enunciado de súmula, de jurisprudência pacificada ou de tese adotada em julgamento de casos repetitivos observará a necessidade de fundamentação adequada e especifica, considerando os princípios da segurança jurídica, da proteção da confiança e da isonomia.I $\$ 5$. Os tribunais darão publicidade a seus precedentes, organizando-os por questão jurídica decidida e divulgando-os, preferencialmente, na rede mundial de computadores".

${ }^{98}$ Tavolari, Raúl, Papel de la Corte Suprema en Chile, en Berizonce, Roberto - Hitters, J.C. - Oteiza, E. (coordinadores) El papel de los Tribunales Superiores. Estudios en Homenaje a A. Morello (Buenos Aires, 2006), p. 471; cfr. Couso, Javier Hilbink, Lisa, From Quietism To Incipient Activism: The Institutional and Ideological Roots Of Rights Adjudication in Chile, en Helmke, Gretchen - Ríos-FigueroA, Julio (coordinadores), Courts in Latin America (Cambridge: 2014), p. 99.

${ }^{99}$ AcCATino, Daniela, El precedente judicial en la cultura jurídica chilena, en 
el Código para, al menos resolver y sentar precedentes horizontalmente. Falta que la Corte Suprema tome conciencia de la necesidad de poner en práctica el principio de justicia formal en orden a que dos causas iguales deben recibir la misma respuesta jurídica ${ }^{100}$. La cultura de la Corte Suprema y la jerarquía administrativa en la organización del poder judicial crean verdaderas convicciones de dependencia, donde el juez inferior es "libre e independiente", pero a su vez sabe que se encuentra subordinado al control del superior, en un rol disciplinario no adjudicativo ${ }^{101}$. Los parámetros de la administración pública o del cuerpo legislativo no resultan aplicables como paradigmas para afrontar la función jurisdiccional ${ }^{102}$. Este primer punto, aunque ajeno al rol en especial que venimos tratando de la Corte Suprema es importante para no confundir sus facultades de superintendencia con rol adjudicativo e interpretativo para constituit precedente. Cabe mencionar que en lo jurisdiccional, donde aún es posible hablar de un tímido minimalismo una corte como cúspide del sistema puede ser ora "tercera instancia" (hace justicia para el caso resolviendo conflictos), ya "casación de ley o más amplia de Derecho" (controla y corrige errores en la interpretación y aplicación del Derecho) o bien de "unificación de jurisprudencia" (decide asumiendo una posición entre varias contradictorias entre sí). Esos roles están ciertamente regulados en relación a la casación en el fondo. A partir de estos tres posibles prismas es posible desarrollar no solo la finalidad de una Corte, sino además las mejores herramientas para aquello que incluyen los medios de impugnación, el interés público y/o privado que persigue como una adecuada división de trabajo o selección

Anuario de Filosofía Jurídica y Social (Valparaíso, 2002): Sobre la cultura jurídica chilena, pp. 559-582.

${ }^{100}$ Atria, Fernando, Proceso civil (La casación como problema), en Revista de Derecho de la Universidad Adolfo Ibáñez, 2 (2005), pp. 275 ss. sostiene que: "En el caso chileno, la crisis de identidad de la casación se produce porque ella está diseñada sobre la base de un modelo de casación en sentido estricto, no de tercera instancia, pero diversos factores la han llevado de un modo que en definitiva ha llegado a ser inevitable hacia el modelo de la tercera instancia. Esos factores incluyen modificaciones legislativas y prácticas de la propia Corte".

${ }^{101}$ Bordali, Andrés, La independencia judicial en el derecho chileno (Santiago, 2010), pp. 67-81.

${ }^{102}$ Cfr. con Ost, François, Dire le droit, faire justice (Bruxelles, 2007), pp. 15-35. Puede hablarse del "Poder Legislativo" y de "Poder Ejecutivo" en tanto siempre actúan en sus funciones legislativas y ejecutivas como tales. No es el diputado o senador " $\mathrm{x}$ " en el procedimiento legislativo los que sancionan una ley, sino el Legislativo. Esta suerte de corporativismo orgánico-funcional no se da en la función jurisdiccional donde actúa en cada caso concreto un juez, o un tribunal colegiado. Impropio sería decir que "representan o actúan en nombre" de una entelequia inexistente como el "Poder Judicial". 
(filtros) de ingreso de causas ya que es imposible que un número reducido de jueces puedan conocer (en términos de calidad y eficiencia) todo lo que ingresa en la base amplia de la pirámide judicial ${ }^{103}$. El "last resort" o "last word" en maeria civil lo tiene la Corte Suprema mediante la verdadera casación (en el fondo, no interesa por ende tratar acá la llamada casación en la forma). La "casación de fondo" sería una vía que operaría a partir de una sumatoria de casos particulares igualmente decididos que generen a la larga una jurisprudencia constante en algunos temas constante. La unificación de jurisprudencia, por su parte, opera, puede sentar pautas generales de interpretación para futuros casos (mecanismo vigente en materia laboral). Nos concentraremos en la casación en el fondo donde interviene exclusivamente la Corte Suprema sin adentrarnos en diferencias comparativas con otros modelos comparados. ${ }^{104}$

b) Contradictorio con lo que vimos en su rol de superintendencia, la Corte Suprema no parece asumir en lo adjudicativo la voluntad de adoptar posiciones que generen uniformidad jurisprudencial y conformen el camino al precedente. Éste, en tanto trato igualitario de los justiciables en base a un interés particular que sirve para el común, generando seguridad y previsibilidad ${ }^{105}$. El recurso aquí en cuestión y de acogerse el recurso que es conocido por las salas especializadas (o eventualmente a requerimiento de cualquiera de las partes por el tribunal en pleno cuando existen fallos contradictorios de las Salas) debe dictar sentencia de reemplazo. Claro que también podría accederse a la Corte Suprema mediante el cuasi-recurso de queja (con un rol disciplinario, pero con resultados jurisdiccionales) frente a una sentencia pronunciada por una Corte de Apelaciones. Finalmente podría conocer del recurso de revisión por cosa juzgada fraudulenta o írrita, que no será referido en este aporte ${ }^{106}$.

${ }^{103}$ Sobre el colapso de los tribunales de justicia en general véase: FIX- Fierro, Héctor, Courts, Justice, and Efficiency: A Socio-Legal Study of Economic Rationality in Adjudication (Oxford, 2003), passim; se tendrá en cuenta especialmente lo sostenido por Taruffo: "La Corte, poi, non è in grado di svolgere la funzione di unificazione della giurisprudenza, e quindi di garantire un grado ragionevole di certezza del diritto, perché una sua giurisprudenza quantitativamente eccessiva y de livello qualitativo mediamente non elevato".

${ }^{104}$ Geeroms, S. M. F., Comparative Law and Legal Translation: Why the Terms Cassation, Revision and Appeal Should Not Be Translated, en American Journal of Comparative Law, 50 (2002,) p. 228.

${ }^{105}$ Sobre el precedente y la relación entre el Tribunal Constitucional y la Corte Suprema, véase: ZúNIIGA URBINA, Francisco, Sentencias del Tribunal Constitucional $y$ del Poder Judicial. El valor del precedente, en Revista de Estudios Constitucionales (Talca, 2006), pp. 151-172.

${ }^{106}$ Véase en detalle un estudio crítico y sobre los antecedentes históricos de la 
c) En este sentido, la casación en el fondo de acuerdo a cómo está regulada en el Código chileno es un acto procesal impugnativo de parte para obtener de la Corte Suprema que las invalide por haberse pronunciado con una infracción de ley que ha influido substancialmente en lo dispositivo del fallo y que la reemplace por otra resolución en que la ley se aplique correctamente. En cuanto a la justificación del recurso de casación en el fondo, la propia exposición de motivos del Código resalta el rol nomofiláctico y uniformador. La casación en el fondo sería la solución a la diversidad de criterios en la aplicación de la ley por los tribunales inferiores. Así, la Corte Suprema sería garante de establecer criterios unitarios en la interpretación y aplicación del derecho. Complementariamente se suele entender que en la casación no existe "instancia”. Por “instancia” la doctrina y jurisprudencia chilena entiende la posibilidad en un grado jurisdiccional de conocer sobre los hechos y el derecho. Al poderse conocer en la casación solo sobre el derecho, pues no habría instancia. Es decir, el legislador optó solo por la existencia de doble instancia no constituyendo la casación una tercera. Ello se debe a que, con la casación en el fondo, la Corte Suprema controla sólo los errores de derecho, pero no los errores de hecho. Por eso existe prohibición de rendir prueba en la casación en el fondo. Los hechos mismos de la causa deben ser reproducidos en el fallo de casación y son los fijados y establecidos por el juez de primera instancia. Ello en teoría es sustentable, pero al ser la causal genérica de casación la infracción de ley, y siendo las reglas que regulan la prueba y su valoración "ley" indirectamente termina abriéndose la puerta a una tercera instancia. Debe mencionarse además que ello se ve favorecido, en la prueba, por tener el Código chileno el medieval sistema de prueba legal o tasada, siendo residual la valoración conforme a la sana crítica. En el mensaje inicial al Código se enuncia: " $L a$ casación en el fondo introduce en nuestra legislación una novedad reclamada por las necesidades de dar uniforme aplicación a las leyes" 107.

d) Se mencionan como características distintivas de la casación: el ser un recurso extraordinario, es decir, cabe excepcionalmente sólo contra algunas resoluciones; el tribunal debe pronunciar dos sentencias, una de casación y otra de reemplazo; es de competencia exclusiva y excluyente de la Corte Suprema; es de derecho estricto. A partir de todo lo mencionado, podemos inferir que la finalidad principal de la Corte Suprema es el control de la correcta aplicación del derecho. Por lo tanto se centra,

casación en ATRIA, cit. (n. 100), pp. 249-353; igualmente y más reciente el excelente aporte de Romero Seguel, Alejandro, El recurso de casación en el fondo civil. Propuestas para la generación de precedentes judiciales (Santiago, 2013), passim.

107 "Mensaje Presidencial” de Jorge Montt y el ministro Máximo del Campo sobre el proyecto de ley de Código de Procedimiento Civil de 1902. 
primordialmente, en un enfoque hacia el ius litigatoris, es decir, centrando su decisión en las peculiaridades del caso concreto. Así, si se prefiere esta perspectiva, la casación será considerada un recurso propiamente tal, con el que se recurre para establecer la justicia en el caso concreto, transformando a la Corte Suprema en un órgano jurisdiccional de última instancia, que se avoca a restablecer el derecho. Se puede llegar a esta conclusión por diversos factores: i) En primer lugar, desde el año 2006, se le arrebató la competencia para conocer de la inaplicabilidad por inconstitucionalidad, la cual fue entregada al Tribunal Constitucional, con lo que la facultad de interpretación general del ordenamiento jurídico se vio robustecida por parte del tribunal kelseniano, en desmedro de la Corte Suprema. ii) En segundo lugar, no tiene facultad explícita para seleccionar aquellas materias que considere trascendentes (ius constitucionis) de ser conocidas, con lo cual se estructura una corte de ultimo grado jurisdiccional, y se resta fuerza vinculante con carácter general, que pudiese reflejar el pensamiento jurídico de la nación. Esto último, repercute en la práctica, puesto que contamos con una orgánica propia de una Corte Suprema, lo que se refleja en su composición de 21 ministros, sin embargo, sus competencias jurisdiccionales la han llevado y la llevan nuevamente al colapso.

El recurso de casación tiene lugar en contra de la sentencia pronunciada con infracción de ley y esta infracción haya influido substancialmente en lo dispositivo de la sentencia (artículo 767 CPC.). Nótese ya en la terminología empleada de "infracción a la ley" cómo influyó la vision casacional decimonónica al poner en el centro el control de la ley, ni siquiera en el Derecho. Podrá verse que en este detalle de "leyes" revisables por la CS mediante el recurso de casación no se menciona el detalle de la norma sobre las leyes, la Constitución ${ }^{108}$. Al respecto la Corte Suprema, no obstante ser usual que mencione en sus fallos violación a la Constitución y tratados internacionales, fue históricamente reacia a incluirla ${ }^{109}$. No obstante parte importante de la doctrina piensa en forma diferente en que se considera incluida $^{110}$.

${ }^{108}$ Romero Seguel, Alejandro, El recuso de casación en el fondo como medio para denunciar la infracción a la Constitución, en Revista Chilena de Derecho, 32 (2005) 3, pp. 495-500; igualmente BORDALI, Andrés, La unidad en la interpretación jurisdiccional de los derechos fundamentales: una tarea pendiente en el derecho chileno, en Revista Chilena de Derecho (2007) 3, pp. 517-538.

${ }^{109}$ Así las sentencias de la Corte Suprema de 30 de octubre de 2002, en Revista de Derecho y Jurisprudencia, 99, sec. $1^{\mathrm{a}}$, pp. 274-279; de 30 de julio de 2002, rol N 3841-2001; de 4 de junio de 2002, rol No 873-2001; y de 17 de abril de 2002, rol $N^{\circ} 2843-2001$.

${ }^{110}$ CaSARIno Mario, Manual de derecho procesal (Santiago, 2007), p. 199: "Es evidente que dentro de la ley formal incluimos a la Constitución Política del Estado, 
e) Podrá verse que determinar la extension de lo que se entiende por "ley" ya es complejo. A ello debe sumarse la disquisición sobre qué se entiende por "infracción”, o de otra manera cómo puede violarse una ley. Qué se entiende por infracción es algo complejo, ya que el numeral primero del artículo 772 CPC. establece que el escrito de casación en el fondo debe indicar los "errores de derecho" en que se incurrió, con lo cual surge la duda de si infracción y error son sinónimos. Las decisiones tomadas por la Corte Suprema no tienen fuerza vinculante directa expresa. No existe súmula, tesis o algo similar. De hecho la importancia de la jurisprudencia en general en Chile solo ha ido aumentando en los últimos 10 años ${ }^{111}$. Ahora bien la Corte Suprema desempeña un rol expreso de unificador de jurisprudencia contradictoria entre sus salas establecido en el código de procedimiento civil frente al supuesto de sentencias contradictorias de las salas. Las partes pueden solicitar que tribunal en pleno se manifieste al respecto, lo que se encuentra contenido del artículo 780, mecanismo que por cierto se usó por primera vez en la historia de la casación chilena en febrero del año 2013, tema al que volveremos en el siguiente punto. Por su parte el Código Procesal Penal establece que el conocimiento del recurso de Nulidad que se fundare en determinadas causales relacionadas con derechos y garantías fundamentales debe ser conocido por la Corte Suprema ${ }^{112}$. En materia penal y por otras causales pueden conocer y decidir el recurso las Cortes de Apelaciones, pero si por estas otras causales llegan a existir distintas interpretaciones en los tribunales superiores corresponderá que la Corte Suprema decida ${ }^{113}$. A ello se suma el establecido

puesto que constituye la ley suprema, y, por consiguiente, su infracción también motivará la procedencia del precitado recurso"; TAVOlari Oliveros, Raúl, Recursos de casación y queja (Santiago, 1996), p. 52: "agotada la polémica respectiva y prevaleciente la idea que la Constitución es la norma de mayor jerarquía en el ordenamiento y que ha de recibir aplicación directa, no es dudoso que, en su infracción pueda encontrarse el error de derecho que hará prosperar el recurso".

${ }^{111}$ Ello ya fue estudiado y denunciado por RoMERo SEGUEL, Alejandro, La jurisprudencia de los tribunales como fuente del derecho: una perspectiva procesal (Santiago, 2004), passim.

${ }^{112}$ Horvitz Lennon, María Inés - López Masle, Julián, Derecho procesal penal chileno (Santiago de Chile, 2005), II, pp. 348-350 y 351- 353.

${ }^{113}$ Cortés Matcovich, Gonzalo, El recurso de nulidad (Santiago, 2006); DelGADO CASTRO, Jordi, La unificación de la jurisprudencia de los recursos procesales: Una referencia a la experiencia española en materia laboral, en Revista de Ciencias Sociales, No 58 (Valparaíso, 2011), pp. 143-174; Ríos Álvarez, Lautaro, Reflexiones acerca del valor determinante del precedente en el sistema jurídico anglosajón y de la fuerza vinculante de la sentencia en el nuestro, en Arancibia, J. - Martínez, I. - Romero, A. (coordinadores), Precedente, cosa juzgada y equivalentes jurisdiccionales en la litigación pública (Santiago, 2013). 
recurso de unificación de la jurisprudencia en materia laboral como medio de unificación autónomo para obtener la unificación frente a dos o más sentencias contradictorias de conocimiento exclusivo y excluyente de la Corte Suprema ${ }^{114}$. Así puede decirse que se desprende de todas estas disposiciones la voluntad del registrador para otorgar el rol de buen formador de la jurisprudencia a la Corte Suprema. La introducción del recurso de unificación de jurisprudencia laboral al ordenamiento jurídico chileno ha venido a reforzar el rol uniformador de la Corte Suprema. Así, a partir de 1995, con la regulación de la vista de la causa por parte del Pleno de la Corte, hasta la introducción del recurso extraordinario en materia civil contenido en el Proyecto de Código Procesal Civil, se puede apreciar cierta intención por parte del legislador chileno en orden a fortalecer y dotar de relevancia jurídica la jurisprudencia que emana del máximo tribunal chileno $^{115}$. Al menos resulta atractiva la propuesta del actual presidente de la Corte Suprema, un pequeño paso, pero paso al fin del precedente horizontal ${ }^{116}$. La Corte Suprema está llamada a asumir sus roles adjudicativos de fijar las líneas interpretativas y establecimiento de precedentes con mayores aspiraciones. En enero del $2013^{117}$ por primera vez a petición de parte tuvo oportunidad de decidir un recurso de casación en el fondo en pleno $^{118}$. Es un antecedente histórico que lo haya hecho, pero lamentable-

${ }^{114}$ Crítica al recurso de unificación en Delgado Castro, Jordi, Examen crítico de la unificación de jurisprudencia, en Revista de Derecho de la PUCV. (2011), pp. 473-494.

${ }^{115}$ Todos tienen acceso a las sentencias de unificación en sede laboral y las materias sobre las que se pronunció véase: http://www.pjud.cl/documents/396729/0/ UNIFICACION+MATERIA+LABORAL.pdf/a8ac22bd-f3d2-4b31-b4d3$256986 f 53053$ (visitado 10 de diciembre de 2014)

${ }^{116}$ Puede verse una referencia del actual presidente de la Corte Suprema a salvaguardar la legítima previsibilidad y confianza frente a un cambio jurisprudencial. En la propuesta original del ministro Sergio Muñoz el "overruling” se regularía del siguiente modo: "La decisión adoptada en relación al recurso pendiente no afectará a los casos anteriores definitivamente resueltos. Por el contrario, dicha decisión tendrá efectos perentorios para los nuevos casos; sin embargo, la Corte Suprema podrá, transcurridos tres años y por razones fundadas, alterar la jurisprudencia” foja 62 . MuÑoz, Sergio, Unificación de jurisprudencia (Asunto administrativo) rol AD- 1682008 (Corte Suprema, Santiago de Chile, 2008), pp. 52 a 63.

${ }^{117}$ En el excelente aporte de Romero SeGUel, cit. (n. 111) se menciona este importante fallo en pleno, el texto publicado por su fecha de publicación en el 2013 no alcanzó a tratar el fallo de la Sala Civil que contravendría un plenario.

${ }^{118}$ Le correspondió decidir (rol No 10665-2011 del 21 de enero de 2013, sentencia de unificación de jurisprudencia) si se aplicaba o no la prescripción del Código Civil a las acciones civiles indemnizatorias emanadas de delitos de lesa humanidad; en pleno se dijo que sí prescribían y era aplicable el Código Civil. Hubo votos en 
mente en septiembre de ese mismo año, solo unos meses después, la Sala Civil (varios de los miembros habían votado en disidencia en el pleno), decidió exactamente sobre la misma materia en contra de lo decidido en el pleno, sin mayor fundamentación de por qué se alejaba de una decision plenaria y solo concentrada a los argumentos del caso particular ${ }^{119}$.

\section{CONSIDERACIONES FINALES}

Las externalidades del precedente judicial entendido como un medio más y relevante para la igual y efectiva tutela de los derechos coadyuvan a "gestionar" coherencia, seguridad, previsibilidad, y especialmente el diálogo entre los diversos tribunales hasta llegar a un argumento legitimante y convincente que pueda ser seguido por los tribunales en sus fallos futuros minimizando el riesgo de error. El precedente es mucho más que simplemente hablar de uno o más fallos que forman parte de la jurisprudencia como fuente del derecho con efecto vinculante "disuasivo". Lo principal es que es un producto y se genera en las relaciones dialógicas (discursivas de diálogo y argumentación) entre los tribunales de justicia. En estos tres ejemplos mencionados lo relevante es el diálogo entre los tribunales y como la fuerza de la razón argumentativa de unos legitiman una decisión que termina siendo seguida por otros, o bien, elevan la vara de la disputa y debe llegarse a una última palabra no porque esa sea la correcta, sino porque se necesita una de carácter "última” que por fuerza de la razón y no solo la fuerza de la autoridad pueda ser seguida. Las decisiones judiciales, desde esta perspectiva, asumen la verdadera función de operar como elementos de prescripción normativa en el ordenamiento jurídico. El problema es cumplir varios objetivos en su función pública, entonces, aunque el "para qué" y "por qué" siguen siendo cuestiones importantes a tener en cuenta, dada la dinámica de la vida social y jurídica, debemos prestar atención

disidencia al respecto. El pleno decidió lo siguiente: i) la acción de carácter civil se encuentra prescrita y que la imprescriptibilidad determinada por la legislación internacional para el aspecto penal, no se extiende al ámbito civil; ii) ninguno de los tratados internacionales citados en el fallo impugnado establece la imprescriptibilidad genérica de las acciones orientadas a obtener el reconocimiento de la responsabilidad extracontractual del Estado o de sus órganos institucionales.

${ }^{119}$ Rol No 3841-12, del 4 de septiembre de 2013. La Segunda Sala de la Corte Suprema afirmó que tratándose de delitos de lesa humanidad la acción civil es imprescriptible y que su carácter es no patrimonial, según lo disponen los principios y normas del derecho internacional de los derechos humanos. Tal decisión es contraria a lo resuelto previamente por el pleno de la Corte Suprema en una sentencia de unificación de jurisprudencia. El fallo de la Sala Civil no solo es breve, sino carente de argumentos de por qué no sigue al plenario. 
también "cómo" esta función puede y debe ser desarrollada ${ }^{120}$. En esta línea, defendemos que el universalismo representa una teoría adecuada para la justificación de la decisión judicial en conformidad con los principios de la igualdad, imparcialidad y racionalidad. La universalidad impone a cada juez o tribunal el deber de coherencia en sus diferentes decisiones y así es posible "tratar las decisiones judiciales previas como enunciados autoritativos del derecho que funcionan como buenas razones para decisiones subsecuentes". Se puede ver que tanto en Brasil como en Chile las cortes supremas asumen varias funciones, la principal relacionada con lo aquí tratado que debiera conciliar finalmente lo activo con lo reactivo, lo público con lo privado. Incluso en la necesidad de generar precedentes el fundamento sigue siendo el mismo para el fin del proceso en tanto otorgar efectiva e igualitaria tutela a los derechos garantizando que la igualdad de trato no es solo igualdad ante la ley sino también ante la jurisprudencia.

\section{BiBLIOGRAFÍA}

Accatino, Daniela, El precedente judicial en la cultura jurídica chilena, en Anuario de Filosofia Jurídica y Social, sobre la cultura jurídica chilena (Valparaíso, 2002).

AleXANDER, Larry - SHERWIN, Emily, Desmystiying Legal Reasoning (Cambridge, 2008). AleXAnder, Larry - Sherwin, Emily, Judges as Rulemakers, Edlin, D. (coordinador), Common Law Theory (Cambridge, 2007).

Alvazzi del Frate, Paolo, Aux origines du référé législatif: interprétation et jurisprudence dans les cahiers de doléances de 1789, Revue Historique de Droit Français et Etranger, 86 (2008) 2.

Andrews, Neil, John Anthony Jolowicz (1926-2012), en European Business Law Review, 4 (2012).

Arens, Peter, Die Befugnis des Revisionsgerichts zur Entscheidung in der Sache selbst, en $A c P 161$ (1962).

ARNIO, AULIS, Lo racional como razonable. Un tratado sobre la justificación jurídica (traducción de Ernersto Garzón Valdez, Madrid, 1991).

ARnold, Hans, Die Neuordnung des Zugangs zum Bundesgerichtshof in Zivilsachen, en Juristische Rundschau (1975).

Atria, Fernando, Proceso civil (La casación como problema), en Revista de Derecho de la Universidad Adolfo Ibáñez 2 (2005).

BARAK, Aharon, The Judges in a Democracy (Princeton, 2006).

Barbosa Moreira, José Carlos, Comentários ao Código de Processo Civil (Rio de Janeiro, 2009).

Bell, John, Sources of Law, en BirKs, P. (coordinador), English Private Law, 1 (Oxford, 2000).

Blackstone, William, Commentaries on the Laws of England, Introduction (Oxford, $1765)$.

${ }^{120}$ JolOWICZ , cit. (n. 16 ), p. 63. 
Bовек, Michal, Quantity or Quality? Re-Assessing the Role of the Supreme Jurisdictions in Central Europe, en American Journal of Comparative Law, 57 (2009).

Bordali, Andrés, La independencia judicial en el derecho chileno (Santiago, 2010).

BORDALI, Andrés, La unidad en la interpretación jurisdiccional de los derechos fundamentales: una tarea pendiente en el derecho chileno, en Revista Chilena de Derecho (2007).

Bueno de Mesquita, Ethan - Stephenson, Matthew, Informative Precedent and Intrajudicial Communication, en American Political Science Review, 196 (2002).

CaDiET, Loïc, Le jugde de cassation en Europe, en Revista de Processo, 209 (São Paulo, 2012).

CapOnI, Remo, La modifica dell'art. 360, 1 comma, n. 5 c.p.c. [disponible en: www. academia.edu] (visitado el 12 de marzo de 2015)].

Cappelletti, Mauro, Dictamen iconoclástico sobre la reforma del processo civil italiano In: Proceso, ideologías, sociedad (traducción de Santiago Santís Melendo y Tomás A. Banzhaf., Buenos Aires, 1980).

CARdozo, Benjamin, The Nature of the Judicial Process (New Haven - London, 1921). CASARINo, Mario, Manual de derecho procesal (Santiago, 2007).

Cortés Matcovich, Gonzalo, El recurso de nulidad (Santiago, 2006).

Couso, Javier - HILbINK, Lisa, From Quietism to Incipient Activism: The Institutional and Ideological Roots of Rights Adjudication in Chile, en Helmke, Gretchen-Rios - Figueroa, Julio (coordinadores), Courts in Latin America (Cambridge, 2014).

DE LA OLIVA Santos, Andrés, Un modelo de casación civil eficaz para el tribunal supremo de España, en Annuario di Diritto Comparato e di Studi Legislativi (Napoli, 2011).

Delgado Castro, Jordi, Examen crítico de la unificación de jurisprudencia, en Revista de Derecho de la PUCV (2011).

Delgado Castro, Jordi, La unificación de la jurisprudencia de los recursos procesales: Una referencia a la experiencia española en materia laboral, en Revista de Ciencias Sociales, 58 (Valparaíso, 2011).

DENTI, Vittorio, Riforma o controriforma del processo civile? Un progetto per la giustizia civile. Rivista di Dirittto Processual, 25 [II serie], 25 (1970).

Dethloff, Nina, Zugang zur Revisionsinstanz, en Zeitschrift für Rechtspolitik (2000).

DíAz MÉndEZ, Marcela, El recurso de unificación de jurisprudencia laboral (Santiago, 2014).

Diсіотті, E., Comp., Controversie, interpretative, pretese di correttezza, giustificazioni, en Pagliatini - Quadri - Sinesio (editores) Scritti in onore di Marco Comporti (Milano, 2018), II.

Domej, Tom, What is an Important Case? Admisibility of Appeals to the Supreme Courts in the German-Speaking Jurisdictions, en VAN RHEE, C.H. - UzELAC, A. (coordinadores), Nobody's Perfect (Cambridge - Antwerp, 2014).

Duxbury, Neil, The Nature and Authority of Precedent, (Cambridge, 2008).

Eisenberg, Melvin, The Nature of the Common Law (Cambridge, 1998).

Eskridge, William - Frickey, Philip, Hart and Sack's The Legal Process: Basic Problems in the Making and Application of Law, (Westbury, N.Y., 1994).

Fernández, Patricio - Ponzetto, Giacomo, "Stare decisis": Rhetoric and Substance, en Journal of Law, Economics and Organization, 28 (2012) 2.

FIX- FIERro, Héctor, Courts, Justice, and Efficiency: A Socio-Legal Study of Economic Rationality in Adjudication (Oxford, 2003).

GAIER, Reinhard, Der moderne liberale Zivilprozess, en Neue Juristische Wochenschrift (2013). 
GaLIC, Anton, Reshaping the Role of the Supreme Courtsin the Countries of the former Yugoslavia, en VAN RheE, C. H. - UzelaC, A., Nobody's perfect (coordinadores) (Cambridge-Antwerp, 2014).

García, José F. - Verdugo, Sergio, Activismo judicial en Chile. ¿Hacia el gobierno de los jueces? (Santiago, 2013).

GasCON, Marina, Rationality and (Self) Precedent: Brief Considerations Concerning the Grounding and Implications of the Rule of Self Precedent, en Archiv für rechts-und sozialphilosophie, 133 (2012).

Gaul, Friedhelm, Zur Frage nach dem Zweck des Zivilprozesses, en Archiv für die civilistische Praxis, 168 (1968).

Geeroms, S. M. F., Comparative Law and Legal Translation: Why the Terms Cassation, Revision and Appeal Should Not Be Translated, en American Journal of Comparative Law, 50 (2002).

Gerhardt, Michael, The Power of Precedent (Oxford, 2008).

GotTwald, Peter, Die Revisionsinstanz als Tatsacheninstanz (Berlin, 1975).

HaHn, Carl (coordinador), Die Gesammten Materialien zur Civilprozeßordnung (Berlin, 1880), I.

Hamilton, Alexander (ps. Publius), The Federalist, 78 (14 de junio de 1788).

Hansford, Thomas - Sprigs II, James, The Politics of Precedent (Oxford, 2006).

Horst-Eberhard, Henke, Die Tatfrage (Berlin \& München, 1966).

Horvitz Lennon, María Inés - López MasLe, Julián, Derecho procesal penal chileno (Santiago de Chile, 2005), II.

Hufteau, Yves-Louis, Le référé législatif et les pouvoirs du juge dans le silence de la loi (Paris, 1965).

Jolowicz, John Anthony, The Role of the Supreme Court at the National and International Level. A General Report, en Yessiou-Faltsi (editor), The Role of the Supreme Courts at the National and International Level. (Thessaloniki, 1998).

Jolowicz, John, Civil Litigation: What is it for? en DWYER (coordinador), The Civil Procedure Rules Ten Years on (Oxford, 2009).

Kerameus, Konstantinos, Corti supreme a confronto: stato dele cose e linee evolutivek, en Rivista Trimestrale di Diritto e Procedure Civile, 53 (1999).

Konzen, Horst Gesetzentwurf und Revisionsurteil, en Wilke, Dieter (editor), Festschrift zum 125 jährigen Bestehen der Juristischen Gesellschaft zu Berlin (Berlin - New York, 1984).

KornHauser, Leweis, Appeal and Supreme Courts, en SANCHIRICO, C. W. (coordinador), Procedural Law and Economics (Massachusets, 2012).

Lames, Peter, Rechtsfortbildung als Prozeßzweck (Tübingen, 1993)

LEIPOLD, Dieter, Zivilprozeß und Ideologie, en Juristenzeitung (1982).

Liebmann, Enrico, A força criativa da jurisprudência e os limites impostos pelo texto da lei, en Revista de Processo, 43 (1986).

Lindblom, Henrik, The Role of the Supreme Courts in Scandinavia, en Scandinavian Studiesk, 50 (2000).

Lindblom, Henrik, The Role of the Supreme Courts in Scandinaviak, en Scadinavian Studies in Law, 39 (2000).

Luhmann, Niklas, Legitimation durch Verfahren, (Neuwied, 1969).

MacCormick, Neil - Summers, R., Interpreting Precedents: A Comparative Study (Aldershot, 1997).

MaCCormick, Neil, Legal Reasoning and Legal Theory (New York, 1978). 
MacCormick, Neil, Rhetoric and the Rule of Law. A Theory of Reasoning (New York, 2005).

MacCormick, Neil, Why Cases Have Rationes and What These Are? en Goldstein (coordinador), Precedent in Law (Oxford, 1987).

Malaurie, Philippe, Les précédents et le droit, en Revue internationale de Droit Comparé, 58 (2016) 2.

MARINONI, Luiz Guilherme, O STJ enquanto corte de precedentes: recompreensão do sistema processual da corte suprema (São Paulo, 2014).

Maultzsch, Felix, Streitentscheidung und Normbildung durch den Zivilprozess, (Tübingen, 2010).

MaY, Artur, Die Revision (Köln, 1995).

MIERSCH, Matthias, Der sogenannte référé législatif. Eine Untersuchung zum Verhältnis Gesetzgeber, Gesetz und Richteramt seit dem 18. Jahrhundert (Baden-Baden, 2000).

Mitidiero, Daniel, Cortes superiores e cortes supremas: do controle à interpretação, da jurisprudência ao precedente (São Paulo, 2013).

Mitidiero, Daniel, Fundamentação e precedente: Dois discursos a partir da decisão judicial, en Mitidiero - Rizzo Amaral (coordinadores) - Maria Angélica Echer Ferreira Feijó (organizadora), Processo Civil. Etudios em homenagem ao professor doutor Carlos Alberto Alvaro de Oliveira (São Paulo, 2012).

Mitidiero, Daniel, Por uma reforma da justiça civil no Brasil, en Revista de Processo, 199 (2011).

Montesquieu, Charles Louis de Secondat, De l'esprit des loix (Geneva, 1748)

Morvan, Patrick, En droit, la jurisprudence est une source de droit, en Revue de la Recherche Juridique (2001) 1.

Mulcahy, Linda, The Collective Interest in Private Dispute Resolutionk, en Oxford Journal of Legal Studies, 33 (2013) 1.

OldFATHER, Chad M., Judging, Expertise, and the Rule of Law, en Washington University Law Review, 89 (2012).

Ost, François, Dire le droit, faire justice (Bruxelles, 2007).

ОтегzA, Eduardo, A função das cortes supremas na América Latina. História, paradigmas, modelos, contradições e perspectivas, em Revista de Process, 187 (2010).

Pawlowski, Hans-Martin, Aufgabe des Zivilprozesses, Zeitschrift für Zivilprozess, 80 (1967).

Pereira, Paula Pessoa, Legitimidade dos precedentes: a universabilidade das decisões do STJ. (São Paulo, 2014).

PFEIFFER, Thomas Internationale Zuständigkeit und prozessuale Gerechtigkeit (Frankfurt a.M., 1995).

Posner, Richard A., The Role of the Judge in the Twenty-First Century, en Boston University Law Review, 86 (2006).

Postema, Gerald, “A Similibus ad Similia”. Analogical Thinkingin Law, en Edun, D. (coordinador), Common Law Theory (Cambridge, 2007).

Proto Pisani, Andrea, Principio d'egualianza e ricorso per cassazione, en Revista de Processo, 191 (2011).

Proto Pisani, Andrea. Crisi della cassazione: la (no più rinviable) necessità di una scelta, en Revista de Processo, 157 (2008).

Puigelier, Catherine, La création du droit (Libres propos sur la norme jurisprudentielle), en Revue de la Recherche Juridique (2004-).

Rechberger, Walter H. - Simotta, Daphne-Ariane, Zivilprozessrecht (Wiren, 2010). 
RimmelspaCher, Brun, Zugangsvoraussetzungen zum Rechtsmittelgericht, en Peter GotTWALD - Herbert Roth (editores), Festschrift für Ekkehard Schumann (Tübingen, 2001).

Ríos Állvarez, Lautaro, Reflexiones acerca del valor determinante del precedentes en el sistema jurídico anglosajón y de la fuerza vinculante de la sentencia en el nuestro, en J. Arancibia - J.I. Martínez - A. Romero (coordinadores), Precedente, cosa juzgada y equivalentes jurisdiccionales en la litigación pública (Santiago, 2013).

Romero Seguel, Alejandro, El recurso de casación en el fondo civil. Propuestas para la generación de precedentes judiciales (Santiago, 2013).

Romero SEguel, Alejandro, El recurso de casación en el fondo como medio para denunciar la infracción a la Constitución, en Revista Chilena de Derecho, 32 (2005) 3.

Romero SEGUel, Alejandro, La jurisprudencia de los tribunales como fuente del derecho: una perspectiva procesal (Santiago, 2004).

Rosenberg, Leo - Schwab Karl, Heinz - GotTwald, Peter, Zivilprozessrecht (München, 2010).

Schauer, Frederick, Precedent, en Stanford Law Review, 571. (1987).

Schauer, Frederick. Why Precedent in Law (and Elsewhere) Is Not Totally (or Even Substantially) About Analogy (August 2007).

Shetreet, Shimon, Creating a Culture of Judicial Independence, en SHETreEt, S. ForsYTH, Ch. (coordinadores.), The Culture of Judicial Independence. Conceptual Fundations and Practical Challenges, (Leiden, 2012).

Siltala, Raimo, $A$ Theory of Precedent (Oxford - Portland, 2000).

SilveSTRI, Elisabetta, Corti supreme europee: acceso, filtri e selezione, en Le Corti Supreme. Atti del convegno svoltosi a Perugia il 5-6 maggio 2000 (Milano, 2001).

SorabjI, John, Englisch Civil Justice (Cambridge, 2014).

STORME, Marcel, Independence of the Judiciary: The European Perspective, en SHETREET, S. - Forsyth, Ch. (coordinadores.), The Culture ofJudicial Independence. Conceptual Fundations and Practical Challenges (Leiden, 2012).

STÜRner, Rolf, Die Aufklärungspflicht der Parteien des Zivilprozesses (Tübingen, 1976).

STÜRnER, Rolf, O Papel dos Tribunais Superiores na Alemanha, en II Seminário Internacional Brasil-Alemanha, en Cadernos do CEJ., 27 (2011)

STÜrner, Rolf, Prozeßzweck und Verfassung, en PRÜTTING, Hanns (editor), Festschrift für Gottfried Baumgärtel (Köln, 1990).

STÜRNER, Rolf, The New Role of Supreme Courts in A Political and Institutional Context From The German Point of View, en Annuario di Diritto Comparato e di Studi Legislativi (Napoli, 2011).

SweET, Alex Stone, Governing with Judges (Oxford, 2000).

TARUFFO, Michele, Le corti supreme europee: acceso, filtri e selezione, en Le corti supreme: atti del convegno svoltosi a Perugia il 5-6 maggio 2000 (Milano: 2001).

TARUfFo, Michele, Le funzioni delle corte supremi. Cenni generali, en Mitidiero, Daniel - Rizzo, Guilherme (coordinadores) - Echer Ferreira Feijó, Maria Angélica (organizadora), Processo civil. Etudios em homenagem ao professor doutor Carlos Alberto Alvaro de Oliveira (São Paulo, 2012).

TARUfFo, Michele, Le funzioni delle corti supreme: cenni generali In Annuario di Diritto Comparato e di Studi Legislativi (Nápoles, 2011), p. 14.

Taruffo, Michele, Precedente e giurisprudenza en Rivista Trimestrale di Diritto e Procedura Civile. anno 61. 3 (2007), p. 796. 
TARuffo, Michele, Una reforma della Cassazione civile? Rivista Trimestrale di Diritto e Procedura Civile (Milano, 2006) 3, p. 755-786.

TARUfFo, Michele, Una reforma della cassazione civile? En Rivista Trimestrale di Diritto e Procedura Civile,3 (2006).

TARUfFo, Michelle, Appeal, cassation, amparo and All That: What and Why? en Estudios en homenaje al doctor Héctor Fix-Zamudio en sus treinta años como investigador de ciencias jurídicas (México, 1988), III.

Tavolari Oliveros, Raúl, Recursos de casación y queja (Santiago, 1996).

Tavolari, Raúl, Papel de la Corte Suprema en Chile, en Berizonce, Roberto - Hitters, J. C. - ОтеIZA, E. (coordinadores), El papel de los Tribunales Superiores. Estudios en Homenaje a A. Morello (Buenos Aires, 2006).

TROCKER, Nicolò, L'Europa delle corti sovranazionali: Una storia di judicial activism tra tutela dei singoli ed integrazione degli ordinamenti giuridici, en Annuario di Diritto Comparato e di Studi Legislativi (Nápoles, 2011).

Unberath, Hannes, Der Zweck der Rechtsmittel nach der ZPO-Reform. Theorie und Praxis, en Zeitschrift für Zivilprozess, 120 (2007).

UzeLAC, Alan, Goals of Civil Justice and Civil Procedure in the Contemporary World, in Goals of Civil Justice and Civil Procedure in Contemporary Judicial Systems (New York - Dordrecht - Heidelberg, 2014).

Van Rhee, C.H. - Uzelac, Alan, The Pursuit of Truth in Contemporary Civil Procedure, en Van Rhee, C. H. - Uzelac, A. (coordinadores) Truth and Efficiency in Civil Litigation (Cambridge - Antwerp, 2012).

Waldron, Jeremy, "Stare decisis" and the Rule of Law: A Layered Approach (NYU School of Law [disponible en: http://ssrn.com/abstract=1942557. p. 25 (visitado el 12 de marzo de 2015)]

Wasserstrom, Richard, The Judicial Decision-Toward a Theory of Legal Justification (Standford, 1961).

ZúNíga Urbina, Francisco, Sentencias del Tribunal Constitucional y del Poder Judicial. El valor del precedente, en Revista de Estudios Constitucionales (Talca, 2006).

Ufficio del Massimario della Corte Suprema di Cassazione [disponível en: www.cortedicassazione.it/Documenti/Relazione\%20Corti\%20Supreme_08.pdf] (visitado el 12 de marzo de 2015)]. 